Hepatitis viral C

Hepatitis $\mathrm{C}$ virus infection

\author{
Pedro A. Poma ${ }^{1}$ \\ 'Profesor, Escuela de Medicina, Universidad de Illinois en Chicago, Chicago, Illinois, EEUU.
}

\begin{abstract}
Resumen
El virus de la hepatitis $\mathrm{C}$ se trasmite por contacto directo con la sangre de la persona infectada. La mayoría de los pacientes no presenta síntomas en la fase aguda o crónica de la hepatitis. Dos a tres décadas después, algunos pacientes progresan a la cirrosis compensada, que también es asintomática. En un examen de sangre, los anticuerpos se presentan como una sorpresa, porque no se les relaciona con un episodio de contagio. Un embarazo ocasiona la posibilidad de efectos negativos de la infección en la madre 0 el niño. El tratamiento actual no ofrece la certeza de cura, dependiendo del genotipo viral, y presenta efectos adversos que pueden ser severos. La cirrosis descompensada causa la mayoría de muertes relacionadas con esta infección; algunos de estos pacientes desarrollan carcinoma hepatocelular. La reproducción viral causa partículas virales diferentes del virus original, característica que ha impedido el desarrollo de una vacuna. Actualmente, la prevención consiste en evitar el contacto con sangre infectada. Este artículo revisa la infección con el virus de la hepatitis $C$, incluyendo los últimos progresos en tratamiento. Es necesario educar a la comunidad acerca de los efectos de este virus en la salud pública.
\end{abstract}

Palabras clave: Hepatitis C, hepatitis viral, inmunología, embarazo, cirrosis hepática.

\begin{abstract}
Hepatitis $\mathrm{C}$ virus is transmitted by direct contract with blood of an infected person. Most patients do not present symptoms during the acute or chronic phases. After two or three decades some patients progress to compensated cirrhosis, still asymptomatic. Antibodies in a blood test often come as a surprise because there is no association with the episode of contagion. Pregnancy brings the possibility of adverse effects to the mother or child. Current therapy does offer certainty of cure, depending on the viral genotype, and provokes adverse effects that might be severe. Decompensated cirrhosis causes most of the deaths associated with this infection; few patients develop hepatocellular carcinoma. Viral reproduction causes viral particles different from the original, characteristic that has prevented the development of vaccines. Current prevention consists in avoiding contact with infected blood. This article reviews infection with hepatitis $\mathrm{C}$ virus including the most recent progress in treatment. There is need to educate the general public about the effects of this virus on public health.
\end{abstract}

Key words: C hepatitis, viral hepatitis, immunology, pregnancy, liver cirrhosis.

An Fac med. 2011;72(4):277-90

Casi al concluir su visita anual, una paciente de 25 años nos pregunta si necesita hacerse la prueba que detecta la presencia del virus de la hepatitis $C$ (VHC). Estaban planeando un embarazo; pero, cuando el esposo, quien goza de buena salud, quiso donar sangre, le informaron que aunque sus pruebas hepáticas eran normales la prueba del VHC era positiva. Debido a una inmunización Rh severa, durante la gestación él recibió tres transfusiones antes de su nacimiento a las 34 semanas.

Para responder a esta pregunta, se revisa la literatura del virus de la hepatitis C, usando Pub Med (www.ncbi. mlm.nih.gov), se selecciona resúmenes relacionados con las características del virus, factores de riesgo, aspectos clí- nicos de la enfermedad, proceso diagnóstico, efectos en el embarazo, complicaciones y recomendaciones para el tratamiento. También, se revisa las referencias bibliográficas de artículos escogidos cuando se considera que amplían el conocimiento actual de la hepatitis C. Este artículo resume las características, prevalencia, complicaciones y tratamiento actual de la hepatitis C.

\section{EL VIRUS DE LA HEPATITIS C}

Este virus pertenece a la familia Flaviviridae, que consiste de una hélice de ARN y fue identificado en $1989^{(1)}$. Se ha descrito 6 genotipos (genotipos del 1 al 6), con más de 50 subtipos ${ }^{(2)}$. La proporción de genotipos varía en otros países ${ }^{(3)}$; en los EE UU, el genotipo 1 es el más común. Parece que este virus no daña a los hepatocitos directamente, y así los niveles virales en la sangre de la persona afectada no tienen relación con la severidad de la histología de las biopsias hepáticas. El daño hepático en la fase crónica de la enfermedad resulta probablemente de la interacción entre el virus y el sistema inmune del individuo (linfocitos citotóxicos y citoquinas específicas) ${ }^{(3)}$.

\section{Prevalencia}

En el mundo, este virus afecta a 170 millones de personas. En los EE UU se estima que la infección con el virus de la hepatitis C afecta $1,3 \%$ a $1,9 \%$ de la población; 2,7 a 3,9 millones de per- 
sonas viven con la infección crónica, y la hepatitis C causa 12000 muertes anuales ${ }^{(3)}$. En el Perú se estima una prevalencia alrededor de $1 \%{ }^{(4-6)}$. En un estudio en Lima, 1994, la prevalencia era $11,7 \%$; este estudio incluyó 1438 muestras de donantes de sangre voluntarios, pacientes en hemodiálisis, pacientes con hepatitis aguda o crónica, pacientes de centro de rehabilitación de abuso de drogas. La prevalencia en donantes era $0,8 \%$, en pacientes en hemodiálisis 59,3\%, en hemofílicos $83,3 \%$, en personas mayores de 39 años $26,0 \%$, en mujeres $27,4 \%$. Controlando el riesgo por edad y sexo, un antecedente de transfusión de sangre aumenta la posibilidad de tener resultados positivos (OR 29,8), así, como haber tenido un trasplante de órgano (OR 9,1), historia de hepatitis (OR 4,9), hospitalización (OR 3,7), uso de drogas intravenosas (OR 3,5), historia de cirugía (OR $2,6)$, acupuntura (OR 2,1), tratamiento dental $(\mathrm{OR}$ 1,2) e inyecciones $(\mathrm{OR}$ 1,04). En este estudio se determinó el genotipo en 50 muestras; el más común fue el genotipo 1 (86\%), luego el genotipo $3(10 \%)$ y el genotipo $2(2 \%)^{(4)}$. El estudio del Banco de Sangre, Ministerio de Salud, 2000 y 2001, mostró una prevalencia de $0,2 \%$ y $0,6 \%$; en la costa $0,28 \%$, sierra $0,20 \%$ y selva $0,28 \%$, en el año 2000; y costa $0,6 \%$; sierra $0,46 \%$ y selva $0,89 \%$, en el año $2001{ }^{(6)}$.

En los EE UU, se estima que 1\% de las mujeres de edad reproductiva tiene la infección crónica. La prevalencia en mujeres embarazadas que usan drogas ilícitas por vía intravenosa es 70\% a 95\%, con transmisión madre-feto (transmisión vertical) de 3\% a 10\%. La transmisión vertical -que es la causa más común de hepatitis $\mathrm{C}$ crónica en niños- ocurre durante el parto, asociada con los niveles virales maternos. La transmisión vertical es muy rara, en ausencia de viremia ${ }^{(7)}$.

\section{Genotipos}

El genotipo 1 es más agresivo que los otros genotipos. Comparando a las personas que permanecieron VHC ARN positivos, las personas que eliminan el virus espontáneamente tienen una mayor prevalencia del genotipo $1(69 \%$ versus $51 \%$ ), con menos probabilidad de ser VHC ARN positivas (OR 0,47), pero presentan cambios histológicos hepáticos más severos (OR 2,03) ${ }^{(8)}$. Se considera que una persona resuelve la infección espontáneamente cuando después de una prueba anti-VHC positiva, la prueba VHC ARN es negativa. Un estudio de 67 pacientes que resolvieron la infección espontáneamente comparados a 62 pacientes con hepatitis C crónica, encuentra que los primeros tienen una reacción humoral leve. La eliminación espontánea del virus está relacionada con una edad más joven, uso intravenoso de drogas ilegales y presencia de hepatitis A aguda o hepatitis B aguda. La reacción humoral intensa probablemente resulta del contacto continuo o repetitivo con el virus ${ }^{(9)}$.

\section{CONTAGIO POR CONTACTOS CON SERVICIOS MÉDICOS Y OTROS}

\section{Transfusión de sangre y administración de productos de la sangre}

La trasmisión de VHC mediante transfusiones de sangre ha disminuido significantemente con la evolución de las técnicas de despistaje de enfermedades virales. La proporción de unidades de sangre contaminada se ha reducido desde $15 \%$, a comienzos de la década de los 80 , a $5 \%$ a mediados de los 80 , con el despistaje de VIH, y a $2,5 \%$ a fines de los 80 , con la determinación de antígenos core HB y niveles de ALT. La probabilidad actual es de una unidad por cada 1 a 2 millones de unidades de sangre. La posibilidad de trasmisión de VIH es similar a VHC, mientras que la posibilidad de trasmisión del virus de la hepatitis B es de 1 en 58000 a 269000 de unidades ${ }^{(10,11)}$.

\section{Contacto con otros servicios médicos}

En pacientes admitidos a un servicio de hematología (Pavía, Italia, 1997-1998), se comunicó una seroconversión de 4,4\% (13/294); todos tenían el geno- tipo $1 b$; el estudio molecular demostró transmisión de paciente a paciente. Los autores recomendaron realizar pruebas de VHC ARN en todas las admisiones a los servicios de hematología, proteger las mucosas, aislamiento de pacientes con neutropenia y no usar productos con dosis múltiples ${ }^{(12)}$. Otro estudio (París) comunica entrevistas de 450 personas VHC positivas sin antecedente de transfusiones o de uso de intravenoso de drogas ilegales, que comparó con 757 controles similares (sexo, edad, lugar de residencia y proporción de enfermedades crónicas). La mayoría (80\%) tenía hepatitis crónica o cirrosis $(65 \%$ genotipo 1$)$. La posibilidad de infección aumentó con admisión a un servicio médico (OR 2,1) o servicio quirúrgico (OR 1,7), tener endoscopia digestiva (OR 1,9), un aborto (OR 1,7), tratamiento ambulatorio por úlceras o heridas de la piel $(\mathrm{OR} 10,1)$, diatermia $(\mathrm{OR} 3,0)$, gama globulina (OR 1,7$)$, inyecciones intravenosas (OR 1,7) o intramusculares (OR 1,4), escleroterapia (OR 1,6), acupuntura (OR 1,5), cocaína intranasal $(\mathrm{OR} 4,5)$, tratamientos de belleza (OR 2,O), pedicura/manicura (OR 1,7) o practicar deportes de contacto (OR 2,3) ${ }^{(13)}$. Otro estudio, que incluyó todos los pacientes nuevos con VHC en 3 clínicas de enfermedades hepáticas (Israel), encontró 29 personas $(0,75 \%)$ en la fase aguda; la mayoría (65\%) había adquirido la infección después de varios procedimientos en varios ambientes clínicos. Comparando con pacientes con otras formas de transmisión, estas personas eran de mayor edad, con relaciones sexuales monógamas. El uso de drogas ilegales intravenosas era la segunda manera más común de contagio ${ }^{(14)}$. En una clínica de Nueva York, que ofreció despistaje gratuito y en la que participaron 283 personas, la prevalencia de VHC $(28,3 \%)$ era similar en hombres y mujeres, con mayor prevalencia en mayores de 70 años (35\%), en los que habían tenido inyecciones intramusculares $(\mathrm{OR} 9,1)$ y en quienes habían recibido transfusiones de sangre (OR 3,2) ${ }^{(15)}$. Todos estos estudios reportan un riesgo de contagio similar a los estudios peruanos ${ }^{(4,6)}$. Un estudio de 
Tabla 1. Precauciones mínimas.

Estas precauciones son necesarias en todo contacto con pacientes, ya sea que haya o no sospecha de infección, en todos los ambientes clínicos. Son utilizadas para proteger al clínico, así como para evitar la propagación de infecciones entre los pacientes.

- Limpieza de las manos (alcohol, jabón)

- Uso de equipo protector (guantes, mandiles, máscaras, protección de ojos)

- Procedimiento aséptico para las inyecciones

- Manejo de las superficies del cuarto del paciente y de los equipos potencialmente contaminados

- Higiene respiratoria: conducta adecuada cuando se tose o estornuda.

Centers for Disease Control and Prevention. Standard Precautions. 2011.

embarazadas (Karachi, Pakistán) comparó 238 controles con 119 pacientes VHC positivas. Ciertas características aumentaban la posibilidad de la infección: multiparidad (OR 1,99), una o más inyecciones (OR 2,33), hospitalización $(\mathrm{OR} 1,78)$ y contacto doméstico con una persona con ictericia o hepatitis $(\mathrm{OR} 3,32)^{(16)}$.

\section{Transmisión sexual}

Este virus ha sido aislado en semen, secreciones vaginales y saliva. Puede trasmitirse sexualmente, pero este no es modo de transmisión eficiente. Un estudio de la prevalencia de VHC en 310 prostitutas, 88 clientes, 168 hombres que tenían sexo con hombres y 147 parejas heterosexuales, y que fueron comparados con 400 controles (donantes voluntarios), halló una prevalencia de $6,4 \%$ en prostitutas, $6,8 \%$ en clientes, $4,2 \%$ en homosexuales, $7,4 \%$ en las parejas heterosexuales y $1,2 \%$ en los donantes voluntarios. La prevalencia en las parejas heterosexuales de pacientes $\mathrm{VHC}+\mathrm{VIH}$ positivos era 2,2 veces mayor que en las parejas con solo $\mathrm{VHC}$ $(9,2 \% \text { versus } 4,1 \%)^{(17)}$.

Durante la vida de la persona infectada, el riesgo de infección sin el uso de condones del compañero sexual sano es de $1 \%$ a $4 \%$. En una relación sexual monógama prolongada no es necesario el uso de protección; sin embargo, si individuos con $\mathrm{VHC}$ tienen varias parejas sexuales, se debe usar protección ${ }^{(3,11)}$. El uso adecuado de condones previene el contagio de otras enfermedades transmitidas sexualmente (VIH, hepatitis B y otras). Un estudio de 2856 pacientes de VHC (Bérgamo,
Italia) encontró $4,7 \%$ con hepatitis B, $2,6 \%$ con $\mathrm{VIH}, 2,1 \%$ de familiares con anticuerpos VHC $(13,8 \%$ de las parejas sexuales, y 2,3\% de los hijos). Estas proporciones eran aún mayores cuando la mujer era la persona con la infección, así como cuando la infección se relacionó con uso de drogas ilegales intravenosas más que a transfusiones ${ }^{(18)}$. Otro estudio evaluó el riesgo de trasmisión sexual en 895 parejas monógamas heterosexuales; estas parejas negaron sexo anal o coito durante la menstruación, habiendo señalado un promedio de 1,8 coitos/semana. Se encontró tres casos (0,37/ 1000 personas-año); la estructura molecular de los virus no era similar entre los miembros de la pareja (el virus tenía otro origen) ${ }^{(19)}$. Una revisión de 80 estudios concluye que el VHC no aumenta el riesgo de contagio en las relaciones monógamas, pero sí en personas con parejas múltiples (aOR 2,2), aunque algunas de estas parejas usaban drogas ilegales intravenosas. El riesgo de contagio era mayor en mujeres con $\mathrm{VIH}$ u otras infecciones sexuales $(\mathrm{aOR}$ $3,3)^{(20)}$.

Tabla 2. Personas con riesgo alto de infección ${ }^{(3)}$.

- Personas que alguna vez han:

- Usado drogas ilegales intravenosas

- Recibido factores de coagulación (antes de 1987)

- Recibido sangre u órganos (antes de 1992)

- Sido tratadas con hemodiálisis

- Tenido ALT elevadas

- Tenido pruebas VIH positivas

- Personas expuestas a sangre VHC positivas a través de la piel o mucosas.

- Hijos de madres VHC positivas.

\section{Contaminación percutánea}

La posibilidad de infección después de penetración con una aguja usada en una persona con virus detectable en sangre es $2 \%$, pero podría ser hasta de $5 \%$. El riesgo es mayor con agujas huecas, porque contienen más sangre. El riesgo de infección es también es mayor que el riesgo de la población en general para personas en hemodiálisis y el personal que los atiende (3). El uso consistente de las recomendaciones mínimas para evitar la propagación de infecciones (Standard Precautions, tabla 1) durante visitas, procedimientos médicos o quirúrgicos, disminuye consistentemente el riesgo de contagio ${ }^{(3)}$. La contaminación ocurre cuando se usa equipos o materiales designados para un solo uso, en más de una persona, como cuando se usa la misma jeringa para administrar inyectables o soluciones intravenosas en varios pacientes. El virus de la hepatitis $\mathrm{C}$ muy raramente se contagia dentro del ambiente familiar; cuando el contagio ocurre, probablemente se debe a contaminación percutánea con sangre del enfermo ${ }^{(3)}$.

\section{Uso de drogas ilegales}

El VHC se transmite a través de la sangre. En un estudio de 1000 personas usando un cuestionario con 27 temas relacionados con factores de riesgo, se encontró una prevalencia de 8,3\%. Los hombres, las personas de mayor edad y de ingresos bajos mostraron una mayor posibilidad de infección; solo $2 \%$ de las personas sin factores de riesgo fueron positivos al virus ${ }^{(21)}$. La mayoría de los casos nuevos (60\%) está relacionada con el uso intravenoso de drogas ilegales. La cultura de personas que usan drogas ilegales incluye compartir agujas, instrumentos y drogas entre los miembros de su grupo. Estos objetos se comparten sin el beneficio de la esterilización y contienen diversas cantidades de sangre de la persona que los acaba de usar. La mitad de las personas que comienza a usar drogas ilegales intravenosas adquiere la infección durante los primeros 6 meses de uso; la mayoría (90\%) en los primeros 12 meses, aun- 
que ya haya dejado de usarlas. El uso de drogas ilegales por otras vías también ha sido asociado con esta infección, como el uso intranasal de cocaína ${ }^{(22)}$.

\section{ASPECTOS CLÍNICOS}

\section{Las fases de la infección}

En los EE UU, los virus de la hepatitis A y $B$ tienen una mayor prevalencia que el virus de la hepatitis $C$ (figura 1), pero su prevalencia ha disminuido desde el empleo de las vacunas contra la hepatitis B y A. La infección con VHC causa hepatitis aguda y hepatitis crónica.

a. Con relación a la fase aguda, en la mayoría de individuos (70\%) no hay síntomas o tienen síntomas leves (falta de apetito, náuseas, vómitos, fiebre y dolor en el cuadrante superior derecho); solo 20\% a 30\% presentan ictericia. En personas con síntomas, estos duran de 2 a 12 semanas ${ }^{(11)}$. El periodo de incubación es de 6 semanas (rango 2 a 24 semanas) ${ }^{(23)}$. El tiempo promedio de seroconversión es de 8 semanas ${ }^{(24)}$ (figura 2). En $80 \%$ de las personas se detecta anticuerpos 15 semanas después de la exposición al virus; en $90 \%$, en 5 meses; en $97 \%$ de personas en 6 meses; la seroconversión ocurre raramente después de nueve meses ${ }^{(25,26)}$. Durante la fase aguda de la infección, la enzima alanina aminotransferasa (ALT) puede estar elevada (>400 IU/L). Los niveles de esta enzima fluctúan durante el curso de la enfermedad. Los niveles normales persistentes no indican necesariamente la eliminación del virus; estos niveles pueden volver a elevarse ${ }^{(25)}$. Algunas personas (15\% a $25 \%$ ) eliminan el virus espontáneamente ${ }^{(27)}$.

b. La mayoría ( $75 \%$ a $85 \%$ ) progresa a la fase crónica, con elevaciones de ALT persistentes o fluctuantes que indican enfermedad activa, en $60 \%$ a $70 \%$ de las personas ${ }^{(27)}$. El resto, $30 \%$ a $40 \%$ de personas, presenta niveles normales de ALT. No se co-

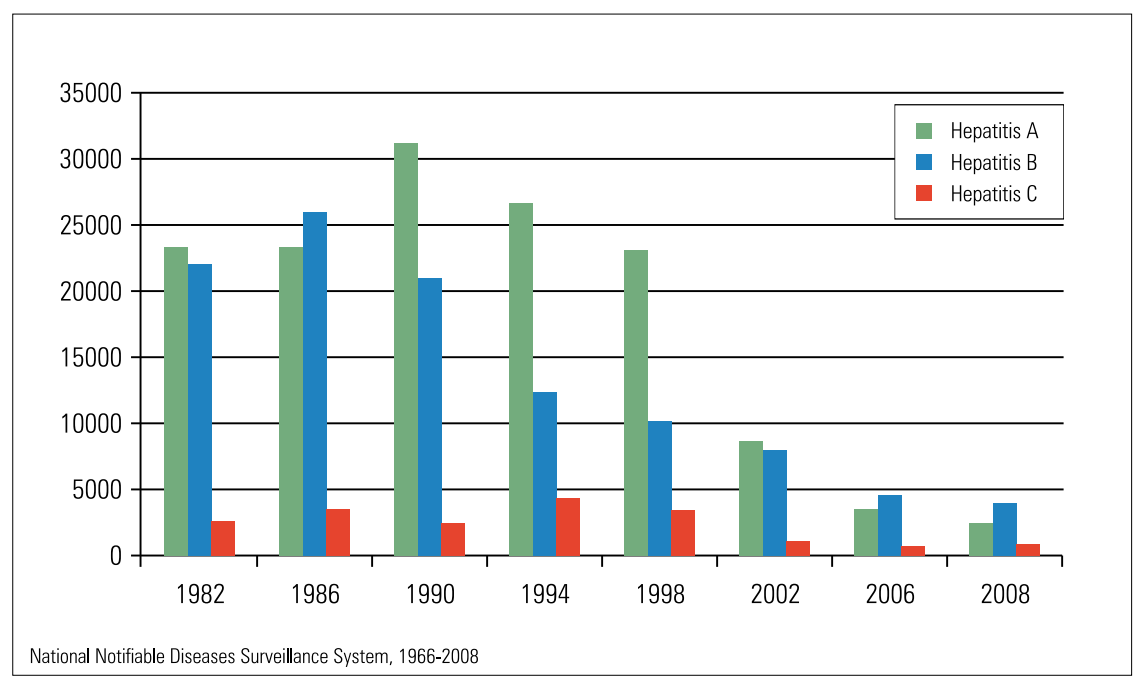

Figura 1. Hepatitis viral, EE UU 1982-2008. noce factores clínicos o epidemiológicos que determinen qué pacientes progresan a la fase crónica. La mayoría de estos pacientes progresa lenta y silenciosamente (no tiene síntomas) por las próximas dos o tres décadas. En 10\% a 20\% de personas con hepatitis $\mathrm{C}$ crónica se desarrolla cirrosis y en $1 \%$ a $5 \%$, carcinoma hepatocelular (CHC) ${ }^{(3,28-30)}$ (figura 2). No se conoce la razón por qué la mayoría de personas progresa a la fase crónica. Podría estar relacionada con la diversidad genética del virus y su tendencia a mutaciones rápidas que previenen su detección por el sistema inmune ${ }^{(31)}$. La infección pasa desapercibida, hasta que exámenes relacionados con donación de sangre o por cualquier otra indicación descubren niveles de ALT elevados, lo que conduce a la determinación del VHC.

\section{Cirrosis}

El progreso a la cirrosis es variable; varía de acuerdo con la edad en que se adquirió la infección, consumo de alcohol, grado de inflamación y fibrosis en biopsias del hígado, coinfección con el virus de la hepatitis B (VHB) o con el virus de la inmunodeficiencia adquirida (VIH), y con la presencia de otras complicaciones ${ }^{(32)}$. En un estudio de 247 pacientes que no habían recibido tra-

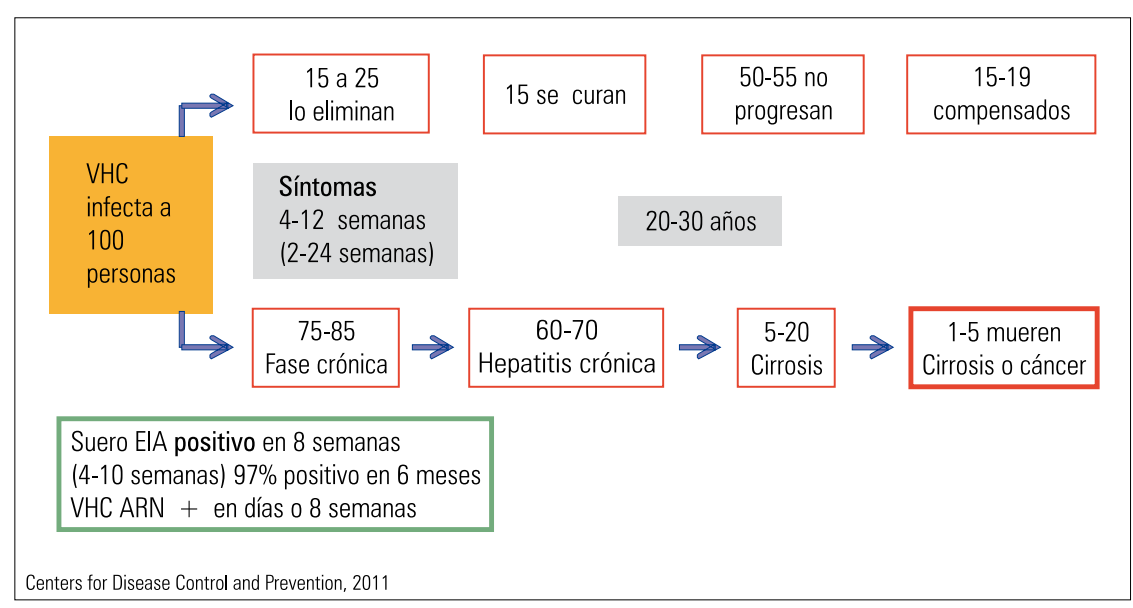

Figura 2. Progreso de la infección por hepatitis C. 
tamiento (Lyon, Francia), se encontró que la fibrosis hepática se acelera con la edad, índice de masa corporal (IMC) $>25$ y los niveles elevados de ALT. La mayoría de pacientes no tratados desarrolló cirrosis alrededor de los 65 años, cualquiera hubiera sido la edad de contagio ${ }^{(33)}$.

Los pacientes con cirrosis relacionada a VHC no presentan síntomas hasta que desarrollan complicaciones; 96\% de los pacientes con cirrosis compensada vive tres años, $91 \%$ cinco años y $79 \%$ diez años. La descompensación clínica se reconoce por la presencia de ascitis, sangrado del tracto digestivo alto (várices o gastropatía portal hipertensiva), síndrome hepatorrenal y encefalopatía hepática. La probabilidad de descompensación clínica es de 5\% durante el primer año del diagnóstico; la probabilidad aumenta a 30\% a los 10 años; con la descompensación, la sobrevivencia baja a 50\%. La cirrosis descompensada causa más muertes relacionadas con la hepatitis $\mathrm{C}$ crónica que el cáncer hepatocelular (CHC). Un metaanálisis de 21 estudios casos-controles estima que el riesgo de $\mathrm{CHC}$ en personas $\mathrm{VCH}$ positivas es 17 veces mayor que en personas VCH negativas ${ }^{(32)}$. Otro estudio evalúa el progreso de la fibrosis hepática en 76 personas con VHC ARN detectable, con duración media de la infección de 13 años, no tratadas, con hígado normal (Knodell $\leq 3$ en dos biopsias) al inicio del estudio y con seguimiento por cuatro años. Durante el seguimiento, 43,4\% de las personas mantuvo niveles normales de ALT; 34\% mostraron progresión de la fibrosis, con evidencia de necrosis e inflamación en la mitad de pacientes. Ni el genotipo o ni el nivel viral afectaron el progreso de la fibrosis. La fibrosis no tuvo evidencia de progreso en la mayoría (66\%) de los que no tenían fibrosis al inicio del estudio. Comparados con pacientes con niveles bajos de ALT, los pacientes con niveles elevados mostraron progreso activo histológico significativo $(1,7$ versus 0,4$)$ o de la fibrosis $(0,9$ versus 0,0$)$. La fibrosis también progresó en personas con un IMC $>25^{\text {(34). }}$.
Se debe evaluar pacientes VHC positivos para determinar la presencia y severidad de la enfermedad hepática crónica ${ }^{(35)}$. La infección con el VHC no protege al individuo de una infección futura con el mismo o con otro genotipo del VHC ${ }^{(35)}$. Los pacientes con infección crónica generalmente tienen niveles más elevados de transaminasas.

\section{La infección oculta}

Se llama infección oculta cuando el VHC ARN está presente en el hígado, pero con pruebas de anticuerpos y VHC ARN negativas. Las pacientes con infección oculta muestran niveles más elevados de colesterol y triglicéridos. Un estudio comparó 68 personas con infección oculta con 69 personas con anticuerpos y VHC-ARN positivos, con características similares (edad, sexo, IMC y duración de pruebas hepáticas anormales). Las personas con infección crónica tuvieron niveles más elevados de gamma globulina, $\alpha$-feto proteína y hierro, mayor actividad inflamatoria, necrosis y fibrosis, que las personas con infección oculta. El porcentaje promedio de hepatocitos infectado también fue mayor en las personas con enfermedad crónica $(10,1 \%)$ que en la enfermedad oculta $(5,3 \%)$; la forma oculta fue menos severa ${ }^{(36)}$.

\section{Carcinoma hepatocelular}

El carcinoma hepatocelular (CHC) es la causa más común de cáncer hepático. Representa la tercera causa más común de muerte en el mundo y la novena en los EE UU, con una incidencia anual de 3,5\%. El CHC es más común en hombres que en mujeres $(5,0$ versus 1,3/100 000 personas al año); 78\% de los casos de CHC en el mundo está asociado con infecciones a virus de las hepatitis $\mathrm{B}$ y $\mathrm{C}{ }^{(37)}$. La determinación de alfa-feto proteína en sangre (AFP, glicoproteína, con niveles normales $<15 \mathrm{ng} / \mathrm{mL}$ ) es comúnmente usada en la evaluación de estos pacientes. Los resultados de la prueba son sugestivos, no diagnósticos; su sensibilidad y valor predictivo positivo son bajos. Además, los pacientes con cirrosis y hepatitis $\mathrm{C}$ crónica pueden tener los niveles elevados, mientras $30 \%$ de pacientes con $\mathrm{CHC}$ tiene niveles normales. Sin embargo, un valor $>400 \mathrm{ng} / \mathrm{mL}$ parece confirmar el diagnóstico. La ecografía del hígado puede detectar lesiones hipoecoides $(<3 \mathrm{~cm})$; las lesiones más grandes generalmente son hiperecoides. La tomografía computarizada o la resonancia magnética son pruebas más específicas ${ }^{(38)}$.

Para evaluar los factores de riesgo del CHC, un estudio de suero sanguíneo obtenido antes del diagnóstico de $\mathrm{CHC}$ en sobrevivientes del ataque atómico en Japón incluyó 224 casos de cáncer y 644 controles similares (edad, sexo, residencia, tiempo de depósito de la muestra y método de depósito). Los factores de riesgo incluyeron hepatitis B (RR 45,8), hepatitis C (RR 101), ambos virus ( $R R 70,7$ ), uso de $>40 \mathrm{~g}$ de etanol/día (RR 4,36), IMC $>25$ por 10 años (RR 4,57), diabetes (RR 1,9) y uso de cigarrillos (RR 2,0); en cambio, tomar café disminuyó el riesgo de $\mathrm{CHC}$ $(\mathrm{RR} 0,5)^{(39)}$.

Los diabéticos con cirrosis tienen mayor riesgo de CHC. En un estudio de 541 pacientes con cirrosis y seguimiento por 4 años (16\% con diabetes, edad media de 50 años), entre los diabéticos 10,5\% tenía puntaje de Ishak 4 (fibrosis hepática forma puentes entre los vasos sanguíneos), 12,5\% puntaje 5 y 19,1\% puntaje 6 (fibrosis extensa, cirrosis). Comparados con $5,9 \%$ de los que no tenían diabetes, $13 \%$ de personas diabéticas desarrollaron CHC. La presencia de fibrosis (Ishak 6) en diabéticos se asoció independientemente con $\mathrm{CHC}$ $(\operatorname{HR} 3,28)^{(40)}$.

Un estudio de la relación entre los niveles de $\alpha$-feto proteína y cirrosis halló AFP $\geq 20$ ng/mL en 16,6\% (191/1145) de pacientes, con niveles de AFP más elevados en mujeres, personas de raza negra, personas con plaquetas disminuidas, niveles elevados de AST y ALT, ferritina, así como la presencia de cuerpos de Mallory en biopsias del hígado. Los niveles de AFP disminuyeron durante el tratamiento. Solo 6 pacientes 
tuvieron CHC, solo 3 de ellos con AFP $>20 \mathrm{ng} / \mathrm{mL}$; sin embargo, los pacientes con hepatitis $\mathrm{C}$ crónica frecuentemente presentaron niveles elevados de AFP en ausencia de cáncer ${ }^{(41)}$.

\section{Consumo excesivo del alcohol}

El consumo excesivo de alcohol aumenta la mortalidad prematura asociada con la infección del virus de la hepatitis C. Un estudio en los EE UU, de 7263163 certificados de defunciones ocurridas durante 2000-2002, comparó personas con la infección que no abusaban del alcohol con personas que no tenían la infección pero que abusaban del alcohol y con personas con la infección que abusaban del alcohol. Comparadas con las muertes no relacionadas con la infección, las muertes relacionadas con el VHC presentaron una mayor prevalencia del abuso del alcohol. Comparando las muertes relacionadas con VHC sin abuso del alcohol, las muertes relacionadas con VHC ocurrieron más temprano en los que abusaban del alcohol (edad promedio: hombres 55,1 versus 50,0 ; mujeres 61,0 versus 49,1 años) ${ }^{(42)}$. Aún el uso moderado de alcohol (>10 g/día) puede acelerar la progresión de la hepatitis (Una botella pequeña de cerveza o un vaso de vino o un trago de whisky contienen casi 15 gramos de alcohol). Parece que el alcohol contribuye a la replicación viral o facilita el daño de las células hepáticas. Aunque ocurre muy raramente, las personas con hepatitis $\mathrm{C}$ que usan alcohol tienen un riesgo mayor de desarrollar hepatitis fulminante ${ }^{(43,44)}$.

\section{VIRUS DE LA HEPATITIS C EN MUJERES}

\section{Influencias endocrinas}

Las mujeres eliminan el virus espontáneamente más efectivamente que los hombres (34\% versus 3\%) ${ }^{(4,45)}$. Los estrógenos y la progesterona afectan la respuesta del individuo. En un estudio de 72 hombres y 71 mujeres (menopausia a los 50 años) con o sin VHC cró- nica encontró que el estradiol inhibe la producción de citoquinas proinflamatorias por las células mononucleares de la sangre periférica de hombres y de las mujeres posmenopáusicas, actividad que protege el hígado; la progesterona se opone a estos efectos favorables ${ }^{(46)}$. Un estudio prospectivo de 251 mujeres con hepatitis $\mathrm{C}$ crónica halló que, comparadas con mujeres con fibrosis hepática leve, la mayoría de mujeres con fibrosis moderada o severa $(67 \%$ versus 47\%) era posmenopáusica. Comparadas con $75 \%$ de personas con fibrosis leve, $24 \%$ de personas con fibrosis moderada o severa tenía una duración mayor de la infección (>15 años), pesaba más y tenía más probabilidad de esteatosis hepática. Sin embargo, la proporción de fibrosis avanzada era menor en las mujeres que usaban hormonas ${ }^{(47)}$. Un estudio de 559 personas en Nueva York señala que, comparadas con personas sin infección, más mujeres con VHC eran posmenopáusicas $(\mathrm{OR} 1,68)$ y sufrían de bochornos (OR 1,52) ${ }^{(48)}$. Estos estudios demuestran un efecto protector de los estrógenos.

\section{Fertilidad}

Esta infección afecta la fertilidad de algunas mujeres. Un estudio retrospectivo comparó 42 ciclos de mujeres con infección crónica con 84 ciclos de mujeres controles; ambos grupos recibieron inyección intracitoplasmática ovular de espermatozoides (Bruselas, Bélgica). Comparadas con las controles, más pacientes presentaron una respuesta menor a la estimulación ovárica (10/42 versus $5 / 84)$ y requirieron más gonadotropinas en los ciclos en que se aspiraba los ovocitos, lo que resultó en número menor de embriones, aunque sus niveles de estradiol y número de ovocitos obtenidos fueron similares ${ }^{(49)}$.

\section{Hepatitis C durante el embarazo}

Esta infección generalmente no tiene un efecto negativo en el embarazo ni en los recién nacidos. En un estudio de 1700 embarazadas (Padua, Italia), con $1,7 \%$ (n 29) VHC positivas, 27/29 con pruebas hepáticas normales durante el embarazo y seis meses después, solo 2/29 tuvieron una elevación mínima de las enzimas hepáticas, con resultados de los embarazos favorables en todas las mujeres ${ }^{(50)}$. En 1994, se descubrió la contaminación con VHC en inmunoglobulina anti D administrada a $36 \mathrm{mu}$ jeres $\mathrm{Rh}$ negativas durante su primer embarazo (Irlanda, 1977-1978). Este estudio, dos décadas más tarde, evaluó 85 embarazos a término, 4 prematuros y 11 abortos espontáneos; solo un niño $(2,3 \%)$ nacido de madre infectada resultó positivo ${ }^{(51)}$. Un estudio retrospectivo de 74629 partos (Dublín Irlanda, 2001-2005) que estudió 559 nacidos vivos de 545 madres VHC positivas encontró una transmisión vertical similar entre las mujeres cuyo diagnóstico fue hecho antes o después del parto, fuera parto vaginal o por cesárea de emergencia, comparados con los nacidos de una cesárea electiva. No se encontró ningún caso de transmisión en madres con VHC ARN negativo ${ }^{(52)}$. Otro estudio de 49 madres con VHC que transmitieron la infección a sus fetos, comparadas con 557 madres con infección pero que no transmitieron la infección, demostró que el uso intravenoso de drogas ilegales era más frecuente en mujeres cuya pareja sexual tenía la infección que en mujeres cuyos compañeros no estaban infectados $(63,9 \%$ versus $21,7 \%$, RR $6,38)$ y que los compañeros sexuales con infección eran más frecuentes en las madres que transmitieron la infección $(46,9 \%$ versus 31,2\%, RR 1,95). La infección paterna no es un factor de riesgo para la trasmisión vertical; su efecto depende del uso intravenoso materno de drogas ilegales ${ }^{(53)}$.

Un estudio de partidas de nacimiento (Washington, EE UU, 2003-2005), que mostró resultados adversos, incluyó 506 embarazadas VHC positivas comparadas con 202 embarazadas VHC negativas y 1439 embarazadas que usaban drogas pero eran VHC negativas. Encontró que los infantes de las mujeres positivas tenían mayor probabilidad de nacer con peso bajo (OR 2,17), necesitar ventilación (OR 2,37) 
y ser admitidos a cuidados intensivos (OR 2,91). Las embarazadas positivas que ganaron mucho peso tuvieron un mayor riesgo de diabetes gestacional (OR 2,51) ${ }^{(54) .}$

\section{La coinfección con VIH}

La infección simultánea con VIH afecta la transmisión vertical de VHC. En un estudio de 441 parejas madre-niño, la transmisión vertical fue $6,7 \%$; la transmisión de $\mathrm{VHC}$ era 3,8 veces más común en mujeres que también eran VIH positivas que en las VIH negativas. La lactancia materna no afectó la transmisión. En este estudio, el parto por cesárea electiva antes de la rotura de membranas disminuyó el riesgo de transmisión comparado con la cesárea de emergencia o el parto vaginal ${ }^{(55)}$. Otro estudio de 86 recién nacidos de madres VHC positivas, con un seguimiento de más de 18 meses (Atenas, Grecia), la transmisión vertical fue $3,6 \%$ y la coinfección con VIH y el uso intravenoso de drogas ilegales aumentó el riesgo de transmisión vertical de VHC; los niños tuvieron el mismo genotipo viral que las madres. El nivel de VHC ARN era más elevado en las madres que transmitieron el virus que en las que no lo transmitieron. La edad materna, tipo del parto, genotipo viral, o tipo de alimentación del recién nacido no afectó la transmisión vertical ${ }^{(56)}$.

Un estudio en Irlanda e Inglaterra de 244 infantes nacidos de madres VHC positivas, con seguimiento durante el primer año de vida de todos los infantes y por 5 años a los que tenían la infección, la transmisión vertical fue 4,7\% (ninguna madre negativa transmitió la infección). Por otro lado, la transmisión vertical fue $3,8 \%$ en madres VHC positivas pero VIH negativas (n 182), comparadas con $25 \%$ en madres VHC$\mathrm{VIH}$ positivas (n 8); 3 de estos infantes se convirtieron VHC ARN negativos durante el seguimiento. La rotura de membranas por 6 o más horas (OR 9,3) y monitoreo fetal interno (OR 6,7) aumentaron la transmisión vertical ${ }^{(57)}$. La mayoría de estudios de embarazadas con hepatitis crónica recomiendan el parto vaginal.

Otro estudio de 48 madres que transmitieron y 122 que no transmitieron la infección encontró que el uso intravenoso de drogas ilegales y la infección de monocitos en sangre periférica eran más frecuentes en niños con la infección (OR 2,33) ${ }^{(58)}$. Un artículo de 157 niños con hepatitis C crónica (Scarborough, ON Canadá, 1990-2001), con 2 o más pruebas de anticuerpos positivas pero negativos a VHC ARN, menciona que $28 \%$ de los niños eliminó la infección; 123 casos de infección adquirida por transfusión eran mayores cuando adquirieron la infección y durante el seguimiento, comparados con 34 casos que no tuvieron transfusión. La edad más joven y niveles normales de ALT estuvieron asociados con la eliminación del virus; $25 \%$ eliminó el virus espontáneamente en 7,3 años ${ }^{(59)}$. Casi $25 \%$ de los niños que adquirió el $\mathrm{VCH}$ al nacer lo eliminó espontáneamente, de acuerdo a un estudio de 266 niños con seguimiento de 4,2 años, 26 con VIH, $10 \%$ con hepatomegalia asociada con un mayor nivel de ALT (OR 4,17) ${ }^{(60)}$. Más de la mitad de personas que recibe sangre en la sala de recién nacidos no lo sabe. Los autores de un estudio comunican que intentaron notificar a 1797 personas que habían recibido sangre contaminada, pero solo pudieron contactar a 216 personas, $3 \%$ de ellos con anticuerpos positivos ${ }^{(61)}$.

\section{Recomendaciones para la embarazada}

Si la mujer no tiene inmunidad, se recomienda vacunarla contra la hepatitis A y la hepatitis B antes del embarazo. Porque aún no se ha evaluado el riesgo fetal, durante el embarazo se evita la vacuna contra la hepatitis A; en cambio, si fuera necesario, se administra la vacuna contra la hepatitis $\mathrm{B}^{{ }^{(62)} \text {. También }}$ se recomienda evitar el alcohol y las drogas hepatotóxicas (acetominofeno, isoniazida, metildopa, fenitoina). Durante la primera visita prenatal, además de las órdenes de rutina, se ordena en- zimas hepáticas y el nivel viral (PCR). Debemos informar al pediatra de la presencia de la infección; prohibir la donación de sangre, tejidos y órganos; prohibir compartir artículos personales que pudieran contener sangre (como las escobillas de dientes y máquinas de afeitar) ${ }^{(3,11)}$. También, debemos confirmar que este virus no se trasmite mediante estornudos, tos, abrazos, agarrarse las manos, compartiendo utensilios de mesa o vasos, o a través de la comida o agua ${ }^{(3,11)}$. El riesgo de contagio para el compañero sexual es bajo, por lo que las personas VHC positivas en una relación monógama de larga duración no necesitará cambiar sus prácticas sexuales, ni hacerse exámenes de laboratorio ${ }^{(3,63)}$.

No se recomienda pruebas VHC de rutina, porque el embarazo no aumenta el riesgo de infección y no existe intervención que disminuya el riesgo de infección del recién nacido. Sin embargo, se recomienda pruebas $\mathrm{VHC}$ en embarazadas con factores de riesgo (tabla 2). Aunque la posición oficial del CDC (Centers for Disease Control and Prevention) y otras organizaciones científicas no lo recomiendan, la AASLD (American Association for the Study of Liver Diseases) sugiere la prueba de anticuerpos en la pareja sexual del paciente ${ }^{(63)}$. La viremia elevada durante el trabajo de parto aumenta el riesgo de transmisión vertical; este riesgo es 2 a 3 veces mayor en la parturienta con coinfección VIH. La mayoría de infantes con infección al nacer no tiene síntomas y tendrán una niñez normal. No hay evidencia de transmisión viral durante la lactancia, pero las madres VHC positivas deben abstenerse de lactar si tienen los pezones rajados o que sangran. En esos niños se ordena pruebas diagnósticas alrededor de los 18 meses de edad para evitar la detección de anticuerpos maternos (transmisión pasiva). Pero, si necesita hacer un diagnóstico temprano, se usa VHC ARN en las visitas de primer o segundo mes. Esta prueba debe ser repetida en las visitas siguientes, cualquiera que fueran los resultados ${ }^{(11)}$. 
Tabla 3. Pruebas diagnósticas.

\begin{tabular}{ccccc} 
Pruebas & ELISA & RIBA & HCV RNA & ALT \\
Hepatitis C crónica & + & + & + & elevada \\
Portador VHC & + & + & + & normal \\
Infección VHC curada & + & + & - & normal \\
Anti-VCH falso positivo & + & - & - & normal \\
\hline
\end{tabular}

Di Bisceglie AM. Hepatitis C. Lancet. 1998;351(9099):351-5.

\section{PROCESO DIAGNÓSTICO}

\section{Diagnóstico de infección}

El diagnóstico de infección VHC requiere una o más de las siguientes 3 pruebas positivas: prueba de anticuerpos (EIA), VHC RIBA (recombinant immunoblot assay), prueba del ácido nucleico (NAT), VHC ARN, además de pruebas negativas de IgM anti-VHA (anticuerpos contra el virus de la hepatitis A) e IgM anti-HBc (antígeno core HB) ${ }^{(11)}$ (tabla 3 y figura 3 ).

\section{Sensibilidad y especificidad}

Los resultados falsos positivos (persona que no tiene la infección) ocurren más frecuentemente en personas de riesgo bajo (donantes de sangre). La mayoría de estas personas tiene pruebas de confirmación negativas, por lo que las pruebas de anticuerpos deben ser confirmadas con la prueba RIBA. Los resultados falsos negativos (persona que tiene la infección) pueden ocurrir en personas que aún no han desarrollado suficientes niveles de anticuerpos para ser detectados por la prueba o en personas que carecen de la respuesta inmune necesaria para producir anticuerpos. La prueba de la PCR (polymerase chain reaction) para VHC ARN ayuda a aclarar la situación ${ }^{(11)}$.

Una prueba VHC ARN (usando RTPCR, reverse transcriptase-polymerase chain reaction) positiva indica presencia de infección. Sin embargo, un resultado VHC ARN negativo en una persona con anticuerpos (prueba de anticuerpos) no diferencia casos de infección resuelta de resultados positivos falsos. Algunas personas con infección pueden tener viremia intermitente, por lo madas con RIBA. Se debe educar a los profesionales en cómo evitar estas circunstancias ${ }^{(11)}$.

\section{CONDICIONES ASOCIADAS CON VHC}

La infección VHC está asociada con un aumento de la posibilidad de otras condiciones clínicas que parecen estar relacionadas con la respuesta individual a la infección; la presencia de estas condiciones no indica mayor severidad de la infección.

\section{Diabetes mellitus}

En los EE UU, la prevalencia de diabetes es 7,8\%; los pacientes con VHC tienen 3 veces más el riesgo de sufrir de diabetes, y los niveles elevados de VHC ARN están asociados con resistencia a la insulina. Un estudio de 162 personas con VHC crónica observó una relación directa entre los niveles VHC ARN con el grado de resistencia a la insulina. La resistencia a la insulina se relacionó directamente con el IMC, nivel de triglicéridos, severidad de la esteatosis hepática y niveles de ALT; pero negativamente con adiponectina ${ }^{(64,65)}$.

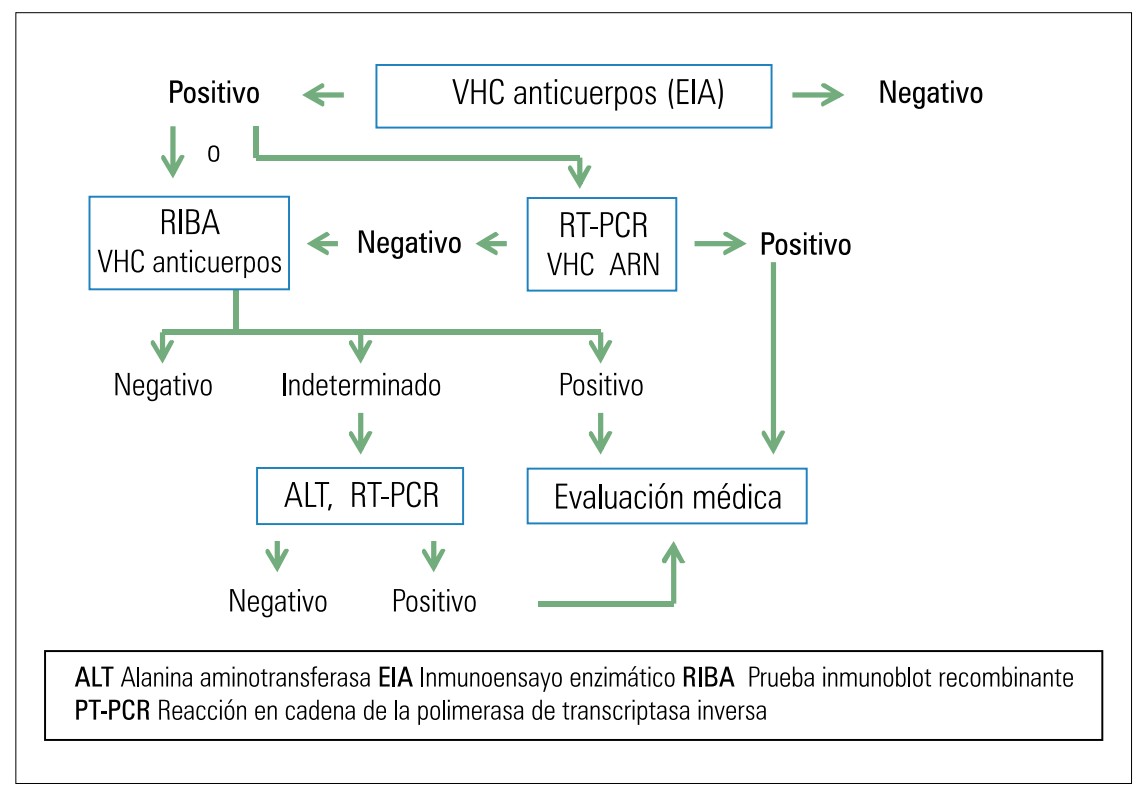

Figura 3. Diagnóstico de la hepatitis $C$ en personas sin sintomas. 


\section{Porfiria cutánea tarda}

Las personas con VHC también presentan un riesgo mayor de desarrollar porfiria cutánea tarda. Cuando la enzima hepática uroporfirinógeno decarboxilasa declina debajo de cierto nivel, aumenta la producción de productos de la porfirina que se acumulan en el hígado y otros órganos. Un reporte de 50 estudios con 2167 pacientes comparó la prevalencia de PCT en pacientes con VHC con controles, resultando $40 \%$ versus $0,24 \%$ (OR 275) ${ }^{(66)}$.

\section{Linfoma no Hodgkins}

Un estudio de 4784 adultos con NHL y 6269 controles (Barcelona, 19882004) confirmó una mayor posibilidad de cáncer de los linfocitos $\mathrm{B}$ o $\mathrm{T}$ en pacientes con VHC, 172 VHC (3,6\%) comparados con 169 controles positi$\operatorname{vos}(2,7 \% \text {, OR } 1,78)^{(67)}$.

\section{Crioglobulinemia}

Consiste en la presencia de inmunoglobulinas anormales que se aglutinan a temperatura $<37^{\circ} \mathrm{C}$, afectando vasos sanguíneos de la piel, articulaciones y riñones (glomerulonefritis). Un estudio retrospectivo (EE UU, 1997-2004) incluyó 145394 pacientes con VHC, 572293 pacientes sin la infección, y controles con características similares. Los pacientes con VHC tenían un mayor riesgo de NHL (aHR 1,28), macroglobulinemia Waldenström (aHR 2,76) y crioglobulinemia (aHR 3,98) ${ }^{(68)}$.

\section{Colestasis intrahepática del embarazo}

La colestasis intrahepática del embarazo (CIH) es una complicación del tercer trimestre del embarazo caracterizada por prurito, que se agrava con el progreso del embarazo, para mejorar después del parto. La CIH está asociada con elevación de los ácidos biliares y las enzimas hepáticas, partos prematuros y una mortalidad fetal de 12 a 30/1 000 nacimientos vivos ${ }^{(69)}$. Un estudio prospectivo de 5840 pacientes (Italia, 1995-1999), con 0,96\% (56/5840) VHC ARN positivos, encontró que la
CIH del embarazo era más común en las mujeres positivas que en las negativas $(20,3 \%$ versus $0,7 \%)$. Los autores recomendaron que las mujeres con $\mathrm{CIH}$ deben ser evaluadas por VHC ${ }^{(70)}$. Otro estudio en un centro de tratamiento de dependencia de drogas de la Universidad de Nueva México (2000-2006), con 351 embarazadas, $53 \%$ con anticuerpos, $47 \%$ negativas, informó que la CIH estaba asociada con la presencia de anticuerpos VHC (6,3\% versus 0\%) ${ }^{(45)}$.

\section{Cirrosis VHC y riesgo de cálculos biliares}

Un estudio en 4867 personas con anticuerpos VHC, $839 \mathrm{HBsAg}$ positivas, 652 con excesivo uso de alcohol, en 79 hospitales (Italia) y en periodo de 6 meses, halló 23,3\% de personas con anticuerpos VHC con cálculos biliares; $12,4 \%$ de personas eran HBsAg positivas y $24,2 \%$ personas con uso excesivo de alcohol. La prevalencia de cálculos biliares aumentó con la edad. Las personas con VHC y cálculos tuvieron más colecistectomías. Al comparar las personas con cirrosis relacionada al $\mathrm{VHB}$, las personas con cirrosis debido a VHC tenían mayor posibilidad de tener cálculos (OR 2,1) ${ }^{(71)}$.

\section{Neuropatía periférica}

La prevalencia de neuropatía periférica es más común en personas con $\mathrm{VCH}$ que en las personas que no tienen la infección. Un estudio de 78 personas, con edad promedio 45,5 años (10 a 75 años), usando un cuestionario y estudio de conducción de los nervios (Acre, Brasil), encontró 34\% de pacientes con parestesias, especialmente de los miembros superiores. En los estudios de conducción, 14,1\% presentó neuropatías múltiples y $5,1 \%$ síndrome carpal ${ }^{(72)}$.

\section{Carcinoma renal}

La infección VHC aumenta el riesgo de enfermedad renal crónica. Un estudio de 67063 personas halló que, comparando pacientes positivos con negativos, el carcinoma renal ocurrió en 0,6\% versus $0,3 \%(\operatorname{HR} 2,20)$ y en personas más jóvenes (edad promedio 54 versus 63) ${ }^{(73)}$.

\section{TRATAMIENTO}

\section{Definiciones}

El objetivo del tratamiento es eliminar al virus (VHC ARN). Existen algunas definiciones que comúnmente son usadas para comunicar la respuesta el tratamiento.

- La respuesta virológica sostenida (RVS, ausencia de VHC ARN detectable usando la prueba RT-PCR o TMA seis meses después del tratamiento) predice la eliminación del virus. En la mayoría de estos pacientes no se detecta VHC ARN en sangre o en el hígado. Las biopsias hepáticas muestran una reducción marcada de la inflamación y de la fibrosis.

- La respuesta virológica rápida (RVR) se refiere a la ausencia del virus después de 4 semanas de tratamiento.

- La respuesta virológica temprana (RVT) denota la reducción de $\geq 2$ log (10) o desaparición completa del VHC ARN en la semana doceava de tratamiento. La respuesta virológica demorada se refiere a la presencia viral en la semana doceava, con ausencia viral en la semana vigésima cuarta. La respuesta de la terminación del tratamiento nos señala la ausencia de virus al final del tratamiento.

- Relapso es cuando al comienzo del tratamiento el paciente responde favorablemente, con desaparición del VHC, pero se vuelve a detectar al virus cuando cesa el tratamiento. Cuando se puede detectar el virus durante la terapia, se dice que la persona no responde al tratamiento ${ }^{(3,11)}$.

\section{Candidatos para el tratamiento}

Son los pacientes con elevación persistente de ALT, con VHC ARN detectable y con fibrosis, inflamación y necro- 
sis (moderada o severa), en la biopsia hepática. El tratamiento con interferón quizás no beneficia a los pacientes con cirrosis compensada (sin ictericia, ascitis, hemorragia de varices esofágicas o encefalopatía). No son candidatos para el tratamiento con interferón los pacientes con niveles normales persistentes de ALT, pacientes en riesgo de descompensación o embarazadas, pacientes que abusan de alcohol o drogas ilegales, hasta que tengan más de 6 meses de abstinencia. No se usa interferón en pacientes con depresión severa, anemia, citopenias, enfermedad cardiaca con síntomas, hipertensión arterial no controlada, diabetes, enfermedad de la tiroides no tratada, recipientes de trasplantes de órganos sólidos, o enfermedad autoinmunes ${ }^{(11)}$.

\section{Tratamiento combinado}

Los interferones son proteínas producidas en respuesta a una infección viral. Interferón pegilado alfa 2a (PegINF $\alpha$-2a) se distribuye en jeringas de $1 \mathrm{~mL}(180 \mu \mathrm{g})$, para administración subcutánea. Ribavirina es un compuesto de nucleótidos ARN de la purina, que interfiere con el mecanismo de replicación viral. Ribavirina se distribuye en tabletas de $200 \mathrm{mg}$. PegINF $\alpha$-2a con ribavirina obtienen $40 \%$ a $80 \%$ de respuesta virológica sostenida (RVS); $80 \%$ en los casos de genotipos 2 o 3, 50\% en casos de genotipo $1^{(3,11)}$. Un estudio aleatorio, doble ciego, de adultos con genotipo 1, que no habían recibido tratamiento, con VHC ARN $>800000 \mathrm{IU} / \mathrm{mL}$, peso $>85$ kg, demostró que Peg-INF $\alpha$-2a 180 o $270 \mu \mathrm{g} / \mathrm{semana}$ con ribavirina 1200 o $1600 \mathrm{mg} /$ diarios por 48 semanas es más efectivo que Peg INF $\alpha$-2a (180 $\mu \mathrm{g} /$ semana) con ribavirina $1600 \mathrm{mg} /$ día y mejor que ribavirina $1200 \mathrm{mg} /$ día. Dosis más altas redujeron RSV (VHC ARN $<50 \mathrm{IU} / \mathrm{mL}$ ) en más pacientes, con menos recurrencias ( $47 \%$ versus $19 \%$ ), pero con más efectos secundarios ${ }^{(74)}$. Otro estudio estudió la administración de Peg-IFN y ribavirina por 48 semanas a 179 hombres y 121 mujeres con VHC genotipo 1 , con un volumen viral $>100$
$\mathrm{KIU} / \mathrm{mL}$. La RVS a las 24 semanas de tratamiento era menos común en las mujeres que en los hombres $\geq 50$ años ( $22 \%$ versus $53 \%)$. Entre los pacientes $\geq 50$ años que recibieron $>80 \%$ de dosis, las mujeres respondieron menos frecuentemente que los hombres $(26 \%$ versus $64 \%$ ). Se considera que los niveles bajos de estrógenos pueden causar esta respuesta más pobre ${ }^{(75)}$. Los pacientes que responden lentamente al tratamiento se benefician con el tratamiento prolongado de 48 a 72 semanas.Sepuedeidentificarapacientes entre las semanas cuarta y duodécima de tratamiento, distinguiendo entre pacientes que responden lentamente $y$ pacientes que no responden al tratamiento. Un estudio muestra menos relapsos y mayor proporción de RSV en pacientes con tratamiento combinado por 72 semanas, comparado con 48 semanas de tratamiento ( $45 \%$ versus $32 \%)^{(76)}$

Los hispanos responden menos favorablemente al tratamiento. Un estudio prospectivo en varios centros médicos (EE UU), 269 hispanos y 300 blancos con VHC genotipo 1 recibieron PegINF $\alpha-2 \mathrm{a}, 180 \mu \mathrm{g} / \mathrm{semana}$ con ribavirina, 1000 o $1200 \mathrm{mg} / \mathrm{día}$, por 48 semanas, con un seguimiento de 72 semanas. Los blancos mostraron una RVS de $49 \%$ comparado con $34 \%$ en hispanos, con desaparición de VCH ARN más frecuentemente en los blancos en la semana cuarta y durante el resto del tratamiento, que en los hispanos ${ }^{(77)}$.

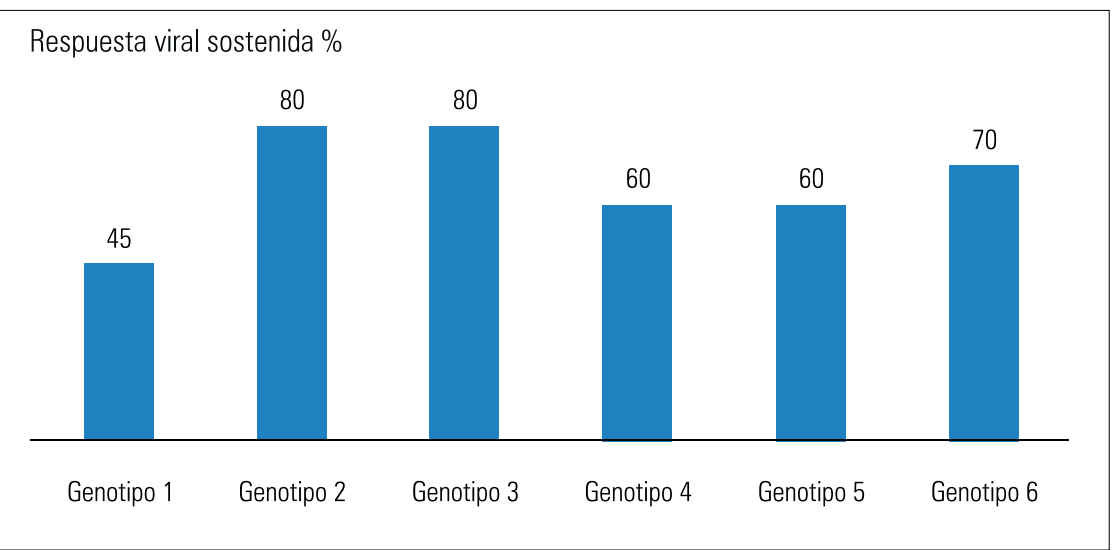

Figura 4. Genotipo y respuesta al tratamiento.
El empleo de ribavirina (categoría X: uso prohibido durante la gestación) está asociado con infertilidad, oligospermia, muerte embrionaria-fetal y malformaciones del esqueleto, cráneo, paladar, ojos, mandíbula, extremidades y aparato digestivo. Las mujeres, para recibir esta medicación, deben de tener pruebas de embarazo negativas mensuales y usar dos métodos anticonceptivos efectivos hasta 6 meses después de concluir el tratamiento. La ribavirina afecta tanto a hombres como a mujeres, por lo que hombres también deben usar métodos para evitar el embarazo hasta 6 meses después del tratamiento ${ }^{(7)}$. Sin embargo, se informa un caso de una mujer embarazada con VHC y VIH (Madrid, España) tratada con ribavirina durante las primeras 16 semanas de gestación, cuyo infante evaluado hasta la edad de 22 meses no mostraba alteración alguna o evidencia de estos virus ${ }^{(78)}$.

La FDA (US Food and Drug Administration) recomienda Peg-INF $\alpha-2$ a (180 $\mu \mathrm{g} / \mathrm{semana})$ vía subcutánea con ribavirina (1 $200 \mathrm{mg} / \mathrm{día})$ por vía oral, en dos dosis, por 48 semanas, para el tratamiento de hepatitis $\mathrm{C}$ crónica con los genotipos 1 o 4 . Como los genotipos 2 o 3 responden mejor al tratamiento, se recomienda ribavirina $800 \mathrm{mg}$ en dos dosis diarias por un periodo de 24 semanas. La FDA no recomienda ribavirina como droga única, porque no es efectiva. Peg-INF $\alpha$-2a obtiene una RVS mayor que Peg-INF $\alpha-2 b{ }^{(79)}$. 
Los resultados del tratamiento combinado varían con el genotipo viral ${ }^{80}$ 82) (figuras 4, 5 y 6). Existen factores que favorecen la eliminación del virus con el tratamiento combinado de la infección crónica, con el genotipo 1 (edad, sexo, raza, otras enfermedades crónicas) ${ }^{(83,84)}$. El polimorfismo de la interleuquina-28B (CC, CT o TT) es otro factor que afecta la respuesta al tratamiento. Un estudio evaluó 1587 personas que no habían recibido tratamiento. En blancos, CC IL-28B se asoció con una mejor RVR (28\% versus CT 5\% y TT 5\%), con RVT completa ( $87 \%$ versus CT $38 \%$ y TT $28 \%$ ) y RVS (69\% versus CT 33\% y TT 27\%). La respuesta entre personas de raza negra e hispanos fue similar ${ }^{(83)}$. Otro estudio comparó 388 personas que eliminaron el virus espontáneamente con 620 con infección persistente; el genotipo CC favoreció la resolución de la infección en individuos de ascendencia europea y africana ${ }^{(84)}$.

\section{Silibinina oral}

El SIL es un compuesto de flavonoides (Legalon SIL; Madaus, Köln, Alemania). Un estudio evaluó pacientes que no respondían al tratamiento IFN + RBV en dosis adecuadas. Después de la administración de SIL $10 \mathrm{mg} / \mathrm{kg} / \mathrm{d}$ por vía intravenosa a 16 pacientes, por 7 días, y de $5,10,15$ o $20 \mathrm{mg} / \mathrm{kg} / \mathrm{d}$ de SIL a 20 pacientes por 14 días; ambos grupos recibieron Peg IFN $\alpha-2 a / R B V$, comenzando en el día 8. El estudio encontró que el volumen viral disminuyó de acuerdo a la dosis ${ }^{(85)}$. La FDA no evalúa productos considerados medicinas naturales.

\section{Telaprevir}

Telaprevir es un inhibidor específico de la proteasa no estructural (NS3/4A) del virus de la hepatitis C. Un estudio de pacientes VHC genotipo 1 que no respondieron al tratamiento con PegINF fueron aleatorizados de la siguiente manera: 115 a T12PR24 (telaprevir 1 $125 \mathrm{mg}$, luego $750 \mathrm{mg}$ cada 8 horas por 12 semanas con Peg INF $\alpha$-2a $180 \mu \mathrm{g} /$ semana y ribavirina 1000 o $1200 \mathrm{mg} /$

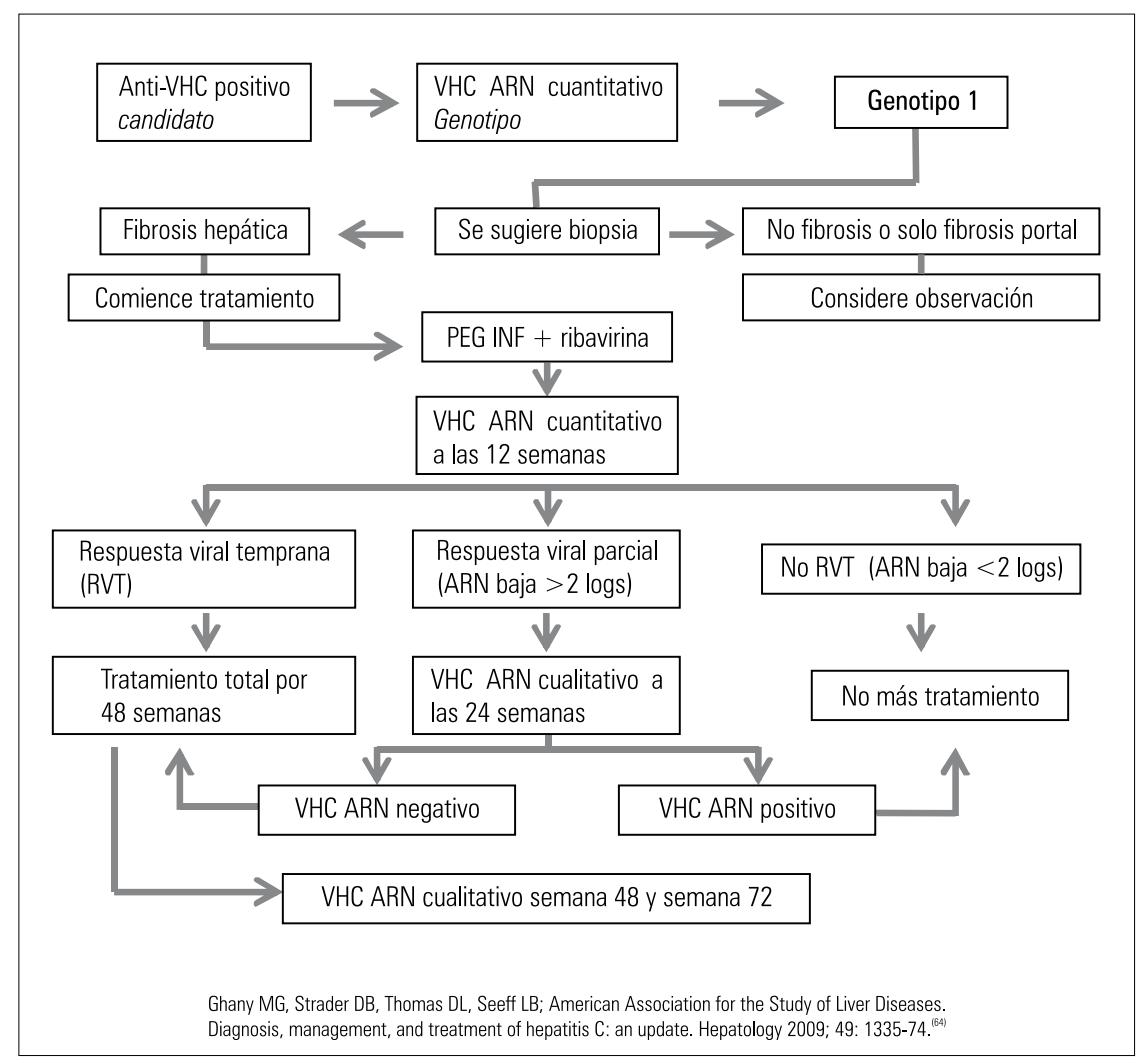

Figura 5. Diagnóstico y manejo de la hepatitis C: genotipo 1.

día por 24 semanas), 113 a T24PR48 (dosis similares telaprevir por 24 semanas con Peg INF $\alpha$-2a con ribavirina por 48 semanas), 111 a T24P24 y 114 a PR 48. La presencia de VHC ARN a las 24 semanas después de la última dosis varió con el grupo: T12PR24, 51\%; T24PR48, 53\%; T24P24, 24\%; PR48, $14 \%$. Sin embargo, la mitad de pacientes $(51 \%)$ presentó erupción cutánea, $5 \%$ severa ${ }^{(86)}$. La FDA ha aprobado el uso de telaprevir (tabletas de 375 mg tres veces al día) en combinación con Peg-INF alfa y ribavirina por doce semanas, para el tratamiento de la hepatitis $\mathrm{C}$ crónica en pacientes con el genotipo 1 .

\section{Boceprevir}

Boceprevir es un inhibidor de la proteasa de la proteína no estructural 3 (NS3) viral. Un estudio evaluó su efectividad en pacientes con el genotipo 1 que no respondían al tratamiento combinado Peg-INF + RBV. Los autores aleatorizaron 403 pacientes que recibían Peg-
INF $\alpha-2 b$ con ribavirina por 4 semanas, a tres grupos. En el grupo 1, los pacientes usaron estos dos medicamentos más placebo, por 44 semanas. En el grupo 2 , los pacientes usaron los dos medicamentos con boceprevir por 32 semanas; a los pacientes con VHC ARN detectable en la semana octava se le agregaba placebo a la combinación por otras 12 semanas. En el grupo 3, los pacientes emplearon las tres medicaciones por 44 semanas. Los grupos con boceprevir tuvieron una mejor respuesta viral (grupo 2, 59\%; grupo 3, 66\%) que el grupo control, 21\%. A las 32 semanas de terapia triple, los pacientes que en la semana octava no tenían niveles detectables del virus tuvieron una mejor RVS $86 \%$, y después de 44 semanas $88 \%$. En 102 pacientes sin disminución del VHC ARN $>10 \mathrm{IU} / \mathrm{mL}$ en la semana cuarta de tratamiento, las RVS eran 0\%, 33\% y $34 \%$, respectivamente ${ }^{(87)}$. En otro estudio doble ciego, después que recibieron Peg-INF $\alpha-2 b+$ ribavirina por 4 semanas, se aleatorizó 938 pacientes 
blancos y 159 pacientes de raza negra con genotipo 1, a uno de 3 grupos. Los pacientes del grupo 1 recibieron placebo más las dos medicaciones, por 44 semanas. A los pacientes del grupo 2 les administraron boceprevir más las dos medicaciones, por 24 semanas; aquellos con VHC ARN detectable entre la semana tercera y vigésima cuarta de tratamiento recibieron placebo más las dos medicaciones por otras 20 semanas. Los pacientes del grupo 3 recibieron boceprevir más las otras dos medicaciones por 44 semanas. En los blancos, las RVS fueron $40 \%$ en el grupo $1,67 \%$ en el grupo 2 y $68 \%$ en el grupo 3 . Las personas de raza negra tuvieron una RVS de $23 \%$ en el grupo $1,42 \%$ en el grupo 2 y $53 \%$ en el grupo $3{ }^{(88)}$.

\section{Peg-IFN lambda}

Es similar a los interferones alfa; usa los mismos mecanismos intracelulares, pero los receptores de interferones alfa están distribuidos en muchos tipos celulares, lo que posiblemente contribuye a los efectos adversos de su tratamiento. Los receptores de IFN lambda se encuentran en los hepatocitos, pero su expresión es menor en las células sanguíneas y otras células no hepáticas. Un reporte preliminar compara tres dosis de Peg-IFN lambda-1 (120, 180 y $240 \mu \mathrm{g})$ con Peg-IFN alfa-2a $180 \mu \mathrm{g}+$ ribavirina, en el tratamiento de pacientes adultos (18 a 70 años), sin cirrosis y sin tratamiento; $60 \%$ eran hombres, la mayoría blancos, con un IMC 26,8 a $27,3 \mathrm{~kg} / \mathrm{m}^{2}, 80 \%$ con genotipo 1 o 4 , los demás con genotipo $2 \mathrm{o} 3$. El uso de IFN lambda resultó en una RVT de $55,9 \%$ comparado con $37,9 \%$ con Peg-IFN y, en los genotipos 2 y 3, RVT $96,6 \%$ comparado con $86,2 \%$. Al confrontar con los pacientes que recibieron Peg-INF alfa-2a, los pacientes que recibieron IFN lambda presentaron menos síntomas parecidos a la gripe $(41,9 \%$ versus 9,7\%), así como menos síntomas relacionados con el sistema músculoesquelético (46,6\% versus $14,2 \%)$. Sin embargo, el Peg-INF lambda causa mayor aumento de la ALT, sobre todo en las dosis más altas ${ }^{(88)}$.

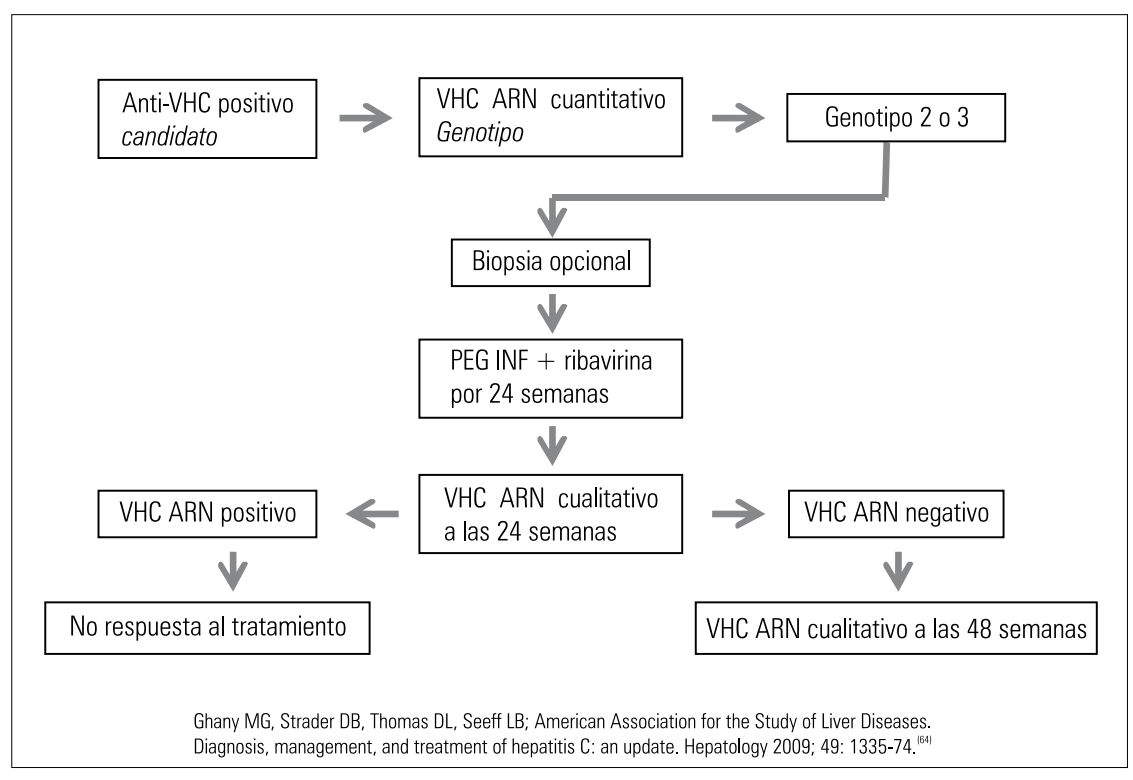

Figura 6. Diagnóstico y manejo de la hepatitis C: genotipos 2 y 3 .

\section{EFECTOS ADVERSOS DEL TRATAMIENTO}

El uso del interferon está comúnmente asociado con síntomas parecidos a la gripe, con pérdida de cabello y con depresión. Estos síntomas mejoran después de las primeras semanas de tratamiento ${ }^{(11)}$. Los efectos menos comunes incluyen la anemia, leucopenia, trombocitopenia y disminución de la función tiroidea. La combinación ribavirina con interferón se asocia con náuseas, tos, disnea, erupciones, prurito, insomnio y pérdida del apetito. La anemia leve se debe a hemólisis, pero puede volverse clínicamente significativa; mejora con la disminución de la dosis y raramente requiere discontinuación ${ }^{(11)}$.

\section{TRASPLANTES DE HÍGADO}

Esta infección es la causa más común de trasplantes de hígado en los EE UU. Después del trasplante, algunos pacientes desarrollan ictericia severa, niveles elevados de VHC ARN, hepatitis en las biopsias del hígado trasplantado. Algunos desarrollan cirrosis en los próximos cinco años. El rechazo agudo del hígado está asociado con niveles elevados del virus. Los esteroides favorecen la reproducción viral. El genotipo 1 b está asociado a hepatitis severa recurrente ${ }^{(7)}$. Las medicaciones para evitar el rechazo del trasplante también tienen efectos adversos. En un estudio de 95 pacientes, con seguimiento de 34 meses, que recibían ciclosporina ( $\mathrm{n} 47$ ) o tacrolimus (n 48) y que fueron comparados con la ciclosporina en pacientes que no recibían terapia antiviral, la recurrencia con tacrolimus era mayor ( $72 \%$ versus $83 \%$ ), mostraban más cambios histológicos asociados con hepatitis C $(87 \%$ versus 100\%), más fibrosis 3 años después (fibrosis estadio $2,66 \%$ versus $90 \%$; fibrosis 3 o $4,46 \%$ versus $80 \%$ ) y más pérdidas del trasplante, debido a recurrencia de la hepatitis C (3 versus 6) ${ }^{(90)}$.

\section{CONCLUSIONES}

Considerando que el VHC fue identificado hace dos décadas, que demora de dos a tres décadas para que las complicaciones se hagan evidentes, que se contagia mediante contactos comunes (inyecciones intramusculares, transfusiones, tratamientos médicos), que a menudo las personas no pueden asociar la fuente del contagio, la proporción de personas con la infección crónica con el virus de la hepatitis $C$ aumentará en los próximos años. Debemos educar al 
público respecto a esta infección viral. En el caso de las mujeres, la paciente no necesita una prueba diagnóstica, pero debe ser informada de que el VHC se contagia mediante el contacto directo con la sangre de una persona con la infección; el pronóstico de un embarazo es bueno, su esposo debe ser evaluado y existe una organización científica que recomienda la prueba.

\section{REFERENCIAS BIBLIOGRÁFICAS}

1. Choo QL, Kuo G, Weiner AJ, Overby LR, Bradley DW, Houghton M. Isolation of a cDNA clone derived from a blood-born viral hepatitis genome. Science. 1989;244(4902):359-62.

2. Simmonds P, Bukh J, Combet C, Deleage G, Enomoto N, Feinstone $S$, et al. Consensus proposals for a unified system of nomenclature of hepatitis $\mathrm{C}$ virus genotypes. Hepatology. 2005;42(4):962-73.

3. Recommendations for Prevention and Control of Hepatitis C Virus (HCV) infection and HCV-related chronic disease. MMWR Recomm Rep. 1998;47(RR 19):1-39,

4. Sanchez JL, Sjogren MH, Callahan JD, Watts DM, Lucas C, Abdel-Hamid M, et al. Hepatitis C in Peru: risk factors for infection, potential iatrogenic transmission, and genotype distribution. Am J Trop Med Hyg. 2000;63(5-6):242-8.

5. Pinto Valdivia JL, Vidal Escudero J, Bussalleu A, Huerta Mercado Tenorio J, Ramirez Vergara D, Valdivia RJ, et al. Hepatitis $\mathrm{C}$ virus infection in blood bank donors at the Hospital Nacional Cayetano Heredia (1998 - 2002). Rev Gastroenterol Peru. 2003;23(1):22-8.

6. Farfan G, Cabezas C. Prevalence of viral hepatitis type $\mathrm{C}$ in blood donors in Peru. Rev Gastroenterol Peru. 2003;23(3):171-6.

7. Wang CC, Krantz E, Klarquist J, Krows M, McBride L, et al. Acute hepatitis $\mathrm{C}$ in a contemporary US cohort: modes of acquisition and factors influencing viral clearance. J Infect Dis. 2007;196(10):1474-82.

8. Harris HE, Eldridge KP, Harbour S, Alexander G, Teo CG, et al. Does the clinical outcome of hepatitis $C$ infection vary with the infecting hepatitis $C$ virus type? J Viral Hepat. 2007;14(3):213-20.

9. Wietzke-Braun P, Manhardt LB, Rosenberger A, Uy A, Ramadori G, Mihm S. Spontaneous elimination of hepatitis $C$ virus infection: a retrospective study on demographic, clinical, and serological correlates. World J Gastroenterol. 2007;13(31):4224-9.

10. Glynn SA, Kleinman SH, Schreiber GB, Busch MP, Wright DJ, Smith JW, et al. Trends in incidence and prevalence of major transfusion-transmissible viral infection in US blood donors, 1991 to 1996. Retrovirus Epidemiology Donor Study (REDS). JAMA. 2000;284(2):229-35.

11. Wang B, Schreiber GB, Glynn SA, Kleinman S, Wright DJ, Murphy EL, et al. Does prevalence of transfusion-transmissible viral infection reflect corresponding incidence in United States blood donors? Transfusion. 2005;45(7):1089-96.

12. Sillini E, Locasciulli A, Santoleri L, Gargantini L, Pinzello $\mathrm{G}$, Montillo M, et al. Hepatitis $\mathrm{C}$ virus infection in a hematology ward: evidence for nosocomial transmission and impact on hematologic disease outcome. Haematologica. 2002;87(11):1200-8.
13. Karmochkine M, Carrat F, Dos Santos O, Cacoub P Raguin $\mathrm{G}$. A case-control study of risk factors for hepatitis $C$ infection in patients with unexplained routes of infection. J Viral Hepat. 2006;13(11):775-82.

14. Lurie $Y$, Landau DA, Blendis L, Baruch $Y$, Veitsman E, Ackermann Z, et al. Acute hepatitis $C$ in Israel: a predominantly iatrogenic disease? J Gastroentero Hepatol. 2007;22(2):158-64.

15. Batash S, Khaykis I, Raicht RF, Bini EJ. High prevalence of hepatitis $C$ virus infection among immigrants from the former Soviet Union in the New York City metropolitan area: results of a communitybased screening program. Am J Gastroenterol. 2008;103(4):922-7.

16. Khan UR, Janjua NZ, Akhtar S, Hatcher J. Casecontrol study of risk factors associated with hepatitis $\mathrm{C}$ virus infection among pregnant women in hospitals of Karachi-Pakistan. Trop Med Int Health. 2008;13(6):754-61.

17. Lissen E, Alter HJ, Abad MA, Torres Y, Pérez-Romero M, Leal M, Pineda JA, Torronteras R, SánchezQuijano A. Hepatitis C virus infection among sexually promiscuous groups and the heterosexual partner of hepatitis $\mathrm{C}$ virus infected index cases. Eur $\mathrm{J}$ Clin Microbiol Infect Dis. 1993;12(11):827-31.

18. Minola E, Baldo V, Baldovin T, Trivello R, Floreani A. Intrafamilial transmission of hepatitis $\mathrm{C}$ virus infection. Eur J Epidemiol. 2006;21(4):293-7.

19. McGinn T, O'Connor-Moore N, Alfandre D, Gardenier D, Wisnivesky J. Validation of a hepatitis C screening tool in primary care. Arch Intern Med. 2008;168(18):2009-13.

20. Division of Viral Hepatitis. Guidelines for Viral Hepatitis Surveillance and Case Management. Centers for Disease Control and Prevention. 2011. Disponible en: www.cdc.gov

21. Vandelli C, Renzo F, Romano L, Tisminetzky S, De Palma M, Stroffolini T, Ventura E, et al. Lack of evidence of sexual transmission of hepatitis $C$ among monogamous couples: results of a 10-year prospective follow-up study. Am J Gastroenterol. 2004;99(5):855-9.

22. Tohme RA, Holmberg SD. Is sexual contact a major mode of hepatitis $C$ virus transmission? Hepatology. 2010;52(4):1497-505.

23. Koretz RL, Brezina M, Polito AJ, Quan S, Wilber J, Dinello R, Gitnick G. Non-A, non-B posttransfusion hepatitis: comparing $C$ and non- $C$ hepatitis. Hepatology. 1993;17(3):361-5.

24. Alter HJ, Tegtmeier GE, Jett BW, Quan S, Shih JW, Bayer WL, Polito AJ. The use of recombinant immunoblot assay in the interpretation of anti-hepatitis C virus reactivity among prospectively followed patients, implicated donors, and random donors. Transfusion. 1991;31(8):771-6.

25. Alter MJ, Margolis HS, Krawczynski K, Judson FN, Mares A, Alexander WJ, Hu PY, et al. The natural history of community-acquired hepatitis $C$ in the United States. The sentinel counties chronic non-A, non-B hepatitis study team. N Engl J Med. 1992;327(27):1899-905.

26. Ridzon R, Gallagher K, Ciesielski C, Ginsberg MB, Robertson BJ, Luo CC, et al. Simultaneous transmission of human immunodeficiency virus and hepatitis $\mathrm{C}$ virus from a needle-stick injury. N Engl $J$ Med. 1997;336(13):919-22.

27. Shakil, AO, Conry-Cantilena, C, Alter HJ, Hayash $\mathrm{P}$, Kleiner DE, Tedeschi $\mathrm{V}$, et al. Volunteer blood donors with antibody to hepatitis $C$ virus: clinical, biochemical, virologic, and histologic features. Ann Intern Med. 1995;123(5):330-7.

28. 28. Di Bisceglie AM, Order SE, Klein JL, Waggoner JG, Sjogren MH, Kuo G, et al. The role of chronic viral hepatitis in hepatocellular carcinoma in the United States. Am J Gastroenterol. 1991;86(3):335-8.

29. Fattovich G, Giustina G, Degos F, Tremolada F, Diodati G, Almasio P, et al. Morbidity and mortality in compensated cirrhosis type $\mathrm{C}$ : a retrospective follow-up study of 384 patients. Gastroenterology. 1997;112(2):463-72.

30. Di Bisceglie AM, Goodman ZD, Ishak KG, Hoofnagle $\mathrm{JH}$, Melpolder JJ, Alter HJ. Long-term clinical and histopathological follow-up of chronic posttransfusion hepatitis. Hepatology. 1991;14(6):969-74.

31. 31. Farci P, Shimoda A, Coiana A, Diaz G, Peddis G, Melpolder JC, et al. The outcome of acute hepatitis C predicted by the evolution of the viral quasispecies. Science. 2000;288(5464):339-44.

32. Chen SL, Morgan TR. The natural history of hepatitis $\mathrm{C}$ virus (HCV) infection. Int J Med Sci. 2006;3(2):47-52.

33. Pradat $\mathrm{P}$, Voirin N, Tillmann HL, Chevallier M, Trépo C. Progression to cirrhosis in hepatitis $C$ patients: an age-dependent process. Liver Int. 2007;27(3):335-9.

34. Sobesky R, Lebray P, Nalpas B, Vallet-Pichard A, Fontaine H, Lagneau JL, Pol S. Pathological evolution of hepatitis $\mathrm{C}$ virus-"healthy carriers". World J Gastroenterol. 2008;14(24):3861-5.

35. National Institutes of Health Consensus Development Conference Panel Statement: Management of Hepatitis C. Hepatology. 1997;26(3 Suppl 1):2S-10S.

36. Pardo M, Lopez-Alcorocho JM, Rodriguez-Inigo E, Castillo I, Carreño V. Comparative study between occult hepatitis $C$ virus infection and chronic hepatitis C. J Viral Hepat. 2007;14(1):36-40.

37. Hepatocellular carcinoma. US 2001-2006. MMWR $59(17) ; 517-20$.

38. El-Seraq HB. Epidemiology of hepatocellular carcinoma en USA. Hepatol Res. 2007;37(Suppl 2):S88-94.

39. Ohishi W, Fujiwara S, Cologne JB, Suzuki G, Akahoshi M, Nishi N, et al. Risk factors for hepatocellular carcinoma in a Japanese population: a nested case-control study. Cancer Epidemiol Biomarkers Prev. 2008;17(4):846-54.

40. Veldt BJ, Chen W, Heathcote EJ, Wedemeyer H, Reichen J, Hofmann WP, et al. Increased risk of hepatocellular carcinoma among patients with hepatitis $\mathrm{C}$ cirrhosis and diabetes mellitus. Hepatology. 2008;47(6):1856-62.

41. Di Bisceglie AM, Sterling RK, Chung RT, Everhart JE, Deinstag JL, Bonkovsky HL, et al. Serum alpha-fetoprotein levels in patients with advanced hepatitis C: results from the HALT-C Trial. J Hepatol. 2005:43(3):434-41.

42. Chen CM, Yoon YH, Yi HY, Lucas DL. Alcohol and hepatitis $C$ mortality among males and females in the United States: a life table analysis. Alcohol Clin Exp Res. 2007;31(2):285-92.

43. Koff, RS, Dienstag, JL. Extrahepatic manifestations of hepatitis $C$ and the association with alcoholic liver disease. Semin Liver Dis. 1995;15(1):101-9.

44. Vento S, Garofano T, Renzini C, Cainelli F, Casali F, Ghironzi $\mathrm{G}$, et al. Fulminant hepatitis associated with hepatitis $A$ virus superinfection in patients with chronic hepatitis C. N Engl J Med. 1998;338(5):286-90.

45. Berkley EM, Leslie KK, Arora S, Qualls C, Dunkelberg JC. Chronic Hepatitis $\mathrm{C}$ in Pregnancy. Obstet Gynecol. 2008;112(2 Pt 1):304-10.

46. Yuan Y, Shimizu I, Shen M, Aoyagi E, Takenaka H, Itagaki $T$, et al. Effects of estradiol and progesterone on the proinflammatory cytokine production by mononuclear cells from patients with chronic hepatitis C. World J Gastroenterol. 2008;14(14):2200-7. 
47. 47. Codes L, Asselah T, Cazals-Hatem D, Tubach F, Vidaud D, Parana R, et al. Liver fibrosis in women with chronic hepatitis $\mathrm{C}$ : evidence for the negative role of the menopause and steatosis and the potential benefit of hormone replacement therapy. Gut. 2007;56(3):390-5

48. Cieloszyk K, Hartel D, Moskaleva G, Schoenbaum EE. Effects of hepatitis $C$ virus infection on menopause status and symptoms. Menopause. 2009 (2);16:401-6.

49. Englert Y, Moens E, Vannin AS, Liesnard C, Emiliani S, Delbaere A, Devreker F. Impaired ovarian stimulation during in vitro fertilization in women who are seropositive for hepatitis $C$ virus and seronegative for human immunodeficiency virus. Fertil Steril. 2007;88(3):607-11.

50. Floreani A, Paternoster D, Zappala F, Cusinato R, Bombi G, Grella P, Chiaramonte M. Hepatitis C virus infection in pregnancy. Br J Obstet Gynaecol. 1996;103(4):325-9.

51. Jabeen T, Cannon B, Hogan J, Crowley M Devereux C, Fanning $L$, et al. Pregnancy and pregnancy outcome in hepatitis C type 1b. QJM. 2000;93(9):597-601.

52. McMenamin MB, Jackson AD, Lambert J, Hall W, Butler K, Coulter-Smith S, McAuliffe FM. Obstetric management of hepatitis C-positive mothers: analysis of vertical transmission in 559 mother-infant pairs. Am J Obstet Gynecol. 2008;199(3):315.e1-5.

53. Indolfi G, Bartolini E, Azzari C, Becciolini L, Moriondo M, de Martino M, Resti M. Intrafamilial transmission of hepatitis $C$ virus: infection of the father predicts the risk of perinatal transmission. J Med Virol. 2008;80(11):1907-11.

54. Pergam SA, Wang CC, Gardella CM, Sandison TG, Phipps WT, Hawes SE. Pregnancy complications associated with hepatitis C: data from a 2003-2005 Washington state birth cohort. Am J Obstet Gynecol. 2008;199(1):38. e 1-9.

55. Gibb DM, Goodall RL, Dunn DT, Healy M, Neave P, Cafferkey M, Butler K. Mother-to-child transmission of hepatitis $C$ virus: evidence for preventable peripartum transmission. Lancet. 2000;356(9233):904-7.

56. Syriopoulou V, Nikolopoulou G, Daikos GL, Theodoridou M, Pavlopoulou I, Ncolaidou P, Manolaki N. Mother to child transmission of hepatitis $C$ virus: rate of infection and risk factors. Scand J Infect Dis. 2005;37(5):350-3.

57. Mast EE, Hwang LY, Seto DS, Nolte FS, Nainan OV Wurtzel H, Alter MJ. Risk factors for perinatal transmission of hepatitis $\mathrm{C}$ virus ( $\mathrm{HCV}$ ) and the natural history of HCV infection acquired in infancy. $J$ Infect Dis. 2005;192(11):1880-9.

58. Azzari C, Moriondo M, Indolfi G, Betti L, Gambiner E, de Martino M, Resti M. Higher risk of hepatitis C virus perinatal transmission from drug user mothers is mediated by peripheral blood mononuclear cell infection. J Med Virol. 2008;80(1):65-71.

59. Yeung LT, To T, King SM, Roberts EA. Spontaneous clearance of childhood hepatitis $\mathrm{C}$ virus infection. J Viral Hepat. 2007;14(11):797-805.

60. European Peadiatric Hepatitis C Virus Network. Three broad modalities in the natural history of vertically acquired hepatitis $C$ virus infection. Clin Infect Dis. 2005;41(1):45-51.

61. Cagle HH, Jacob J, Homan CE, Williams JL, Christensen CJ, McMahon BJ. Results of a general hepatitis $\mathrm{C}$ lookback program for persons who received blood transfusions in a neonatal intensive care unit between January 1975 and July 1992. Arch Pediatr Adoslesc Med. 2007;161(2):125-30.

62. Centers for Disease Control and Prevention. Advisory Committee on Immunization Practices.
Guidance for vaccine recommendations in pregnant and breastfeeding women. Reviewed March 2011. Disponible en: www.cdc.gov

63. Paternoster DM, Santarossa C, Grella P, Palu G, Baldo V, Boccagni P, Floreani A. Viral load in HCV RNA-positive pregnant women. Am J Gastroenterol. 2001;96(9):2751-4.

64. Ghany MG, Strader DB, Thomas DL, Seeff LB; American Association for the Study of Liver Diseases. Diagnosis, management, and treatment of hepatitis C: an update. Hepatology. 2009;49(4):1335-74.

65. Hsu CS, Liu CJ, Liu CH, Wang CC, Chen CL, Lai MY, Chen PJ, et al. High hepatitis C viral load is associated with insulin resistance in patients with chronic hepatitis C. Liver Int. 2008;28(2):271-7.

66. Gisbert JP, Garcia-Buey L, Pajares JM, MorenoOtero R. Prevalence of hepatitis $C$ virus infection in porphyria cutanea tarda: systematic review and meta-analysis. J Hepatol. 2003;39(4):620-7.

67. de Sanjose S, Benavente Y, Vajdic CM, Engels EA, Morton LM, Braccci PM, Spinelli JJ, et al. Hepatitis $\mathrm{C}$ and non-Hodgkin lymphoma among 4784 cases and 6269 controls from the International Lymphoma Epidemiology Consortium. Clin Gastroenterol Hepatol. 2008;6(4):451-8.

68. Giordano TP, Henderson L, Landgren O, Chiao EY, Kramer JR, El-Serag H, Engels EA. Risk of non-Hodgkin lymphoma and lymphoproliferative precursor diseases in US veterans with hepatitis C virus. JAMA. 2007;297(18):2010-7.

69. Fretts RC. Etiology and prevention of stillbirth. Am J Obstet Gynecol. 2005;193(6):1923-35.

70. Paternoster DM, Fabris F, Palu G, Santarossa C, Bracciante R, Snijders D, Floreani A. Intra-hepatic cholestatis of pregnancy in hepatitis $C$ virus infection. Acta Obstet Gynecol Scand. 2002;81(2):99-103.

71. Stroffolini T, Sagnelli E, Mele A, Cottone C, Almasio PL; Italian Hospitals' Collaborating Group. HCV infection is a risk factor for gallstone disease in liver cirrhosis: an Italian epidemiological survey. J Viral Hepat. 2007;14(9):618-23.

72. Gomes I, Nora DB, Marquezini NC, Said G, Melo A. Peripheral neuropathy in patients with hepatitis virus $\mathrm{C}$ infection in the Amazon region. Arq Neuropsiquiatr. 2006;64(3A):600-2.

73. Gordon SC, Moonka D, Brown KA, Rogers C, Huang MA, Bhatt N, Lamerato L. Risk for Renal cell carcinoma in chronic hepatitis $\mathrm{C}$ infection. Cancer Epidemiol Biomarkers Prev. 2010;19(4);1066-73.

74. Fried MW, Jensen DM, Rodriguez-Torres M, Nyberg LM, Di Bisceglie AM, Morgan TR, Pockros PJ, et al. Improved outcomes in patients with hepatitis C with difficult-to-treat characteristics: Randomized study of higher doses of peginterferon alpha-2a and ribavirin. Hepatology. 2008;48(4):1033-43.

75. Sezaki H, Suzuki F, Kawamura Y, Yatsuji H Hosaka $\mathrm{T}$, Akuta M, Kobayashi M, et al. Poor response to Pegilated Interferon and Ribavirin in older women infected with Hepatitis C virus genotype $1 \mathrm{~b}$ in high viral loads. Dig Dis Sci. 2009;54(6):1317-24.

76. Marcellin P, Heathcote EJ, Craxi A. Which patients with genotype 1 chronic hepatitis $C$ can benefit from prolonged treatment with the 'accordion' regimen? J Hepatol. 2007;47(4):580-7.

77. Rodriguez-Torres M, Jeffers LJ, Sheikh MY, Rossaro L, Ankoma-Sey VM, Hamzeh FM, Martin P, et al. Peginterferon alfa-2a and ribavirin in Latino and non-Latino whites with hepatitis C. N Engl J Med. 2009;360(3):257-67.

78. Labarga P, Pinilla J, Cachorro I, Ruiz Y. Infant of 22 months of age with no anomalies born from a HCV- and HIV-infected mother under treatment with pegylated Interferon, ribavirin and antiretroviral therapy during the first 16 weeks of pregnancy. Reprod Toxicol. 2007:24(3-4):414-6.

79. Awad T, Thorlund K, Hauser G, Stimac D, Mabrouk M, Gluud C. Peginterferon alpha-2a is associated with higher sustained virological response than peginterferon alfa-2b in chronic hepatitis $C$ : systematic review of randomized trials. Hepatology. 2010;51(4):1176-84.

80. Zeuzem S. Heterogeneous virologic response rate to inferferon-based therapy in patients with chronic hepatitis CL: who responds less well? Ann Intern Med. 2004;140(5):370-81.

81. Hadziyannis SJ, Sette H Jr, Morgan TR, Balan V, Diago M, Marcellin P, Ramadori G, et al. Peginterferon-alpha 2a and ribavirin combinations therapy in chronic hepatitis $\mathrm{CL}$ : a randomized study of treatment duration and ribavirin dose. Ann Intern Med. 2004;140(5):346-55.

82. Nguyen MH, Keeffe EB. Prevalence and treatment of hepatitis C virus genotypes 4, 5, 6. Clin Gastroenterol Hepatol. 2005;3(10 Suppl 2):S97-S101.

83. Thompson AJ, Muir AJ, Sulkoswski MS, Ge D, Fellay J, Shianna KV, Urban T, et al. Interleukin$28 \mathrm{~B}$ polymorphism improves viral kinetics and is the strongest pretreatment predictor of sustained virologic response in genotype 1 hepatitis $C$ virus. Gastroenterology. 2010;139(1):120-9.

84. Thomas DL, Thio Cl, Martin MP, Qi Y, Ge D, O'Huigin C, Kidd J, et al. Genetic variation in IL28B and spontaneous clearance of hepatitis $C$ virus. Nature. 2009;461(7265):798-801.

85. Ferenci $P$, Scherzer TM, Kerschner H, Rutter $K$, Beinhardt S, Hofer $\mathrm{H}$, Schoniger-Hekele M, et al. Silibinin is a potent antiviral agent in patients with chronic hepatitis $\mathrm{C}$ non responding to pegylated interferon/ribavirin therapy. Gastroenterology. 2008;135(5):1561-7.

86. 86. McHutchison JG, Manns MP, Muir AJ, Terrault NA, Jacobson IM, Afdhal NH, Heathcote EJ, et al. Telaprevir for previously treated chronic HCV infection. N Engl J Med. 2010;362(14):1292-303.

87. Bacon BR, Gordon SC, Lawitz E, Marcellin P, Vierling JM Zeuzem S, Poordad F, et al. Boceprevir for previously treated chronic HCV genotype 1 infection. N Engl J Med. 2011;364(13):1207-17.

88. Poordad F, McCone J Jr, Bacon BR, Bruno S, Manns MP Sulkowski MS, Jacobson IM, et al. Boceprevir for untreated chronic HCV genotype 1 infection. N Eng J Med. 2011;364(13):1195-206.

89. Zeuzem S. European Association for the Study of the Liver (EASL) 46th Annual Meeting. Abril 2, 2011.

90. Villamil F, Levy G, Grazi GL, Mies S, Samuel D, Sanjuan F, Rossi M, et al. Long-term outcomes in liver transplant patients with hepatic $\mathrm{C}$ infection receiving tacrolimus or cyclosporine. Transplant Proc. 2006;38(9):2964-7

Artículo recibido para publicación el 16 de junio de 2011 y aceptado para publicación el 15 de agosto de 2011.

Financiamiento: ninguno.

Conflictos de interés: ninguno.

\section{Correspondencia:}

Pedro A. Poma, MD

505 N Lake Shore Drive, \# 4312

Chicago, Illinois 60611-3465, USA

Teléfono: 3123290668

Correo electrónico: palpoma@yahoo.com. 